\title{
Molecular Genetics and Biology of Head and Neck Squamous Cell Carcinoma: Implications for Diagnosis, Prognosis and Treatment
}

\author{
Federica Ganci, Andrea Sacconi, Valentina Manciocco, Renato Covello, \\ Giuseppe Spriano, Giulia Fontemaggi and Giovanni Blandino \\ Regina Elena Cancer Institute \\ Italy
}

\section{Introduction}

Head and neck cancers are different types of tumours found in the upper aero-digestive tract. The vast majority of them (more than 90\%) are squamous cell carcinomas (HNSCC) that originate in the epithelium lining of the oral cavity, pharynx and larynx. There is a higher incidence rate in males compared to females (Ragin et al, 2007). The median age of patients with HNSCC is about 60 years (Ragin et al, 2007). Young patients make up 1-8\% (Llewellyn et al, 2004). HNSCC comprise 5.5\% of all incidence cancers (Mitra et al, 2007) and is the sixth leading cancer worldwide with approximately 600,000 cases reported annually (Leemans et al, 2011). Local recurrence affects about $60 \%$ of patients and metastases develop in $15-20 \%$ of cases (Choi \& Chen, 2005). About $40-50 \%$ of patients with HNSCC survive for 5 years (Leemans et al, 2011). About one third of patients are diagnosed with early-stage disease, whereas the majority are diagnosed with advanced stage cancer with lymph node metastases. Early stage tumours are treated by surgery or radiotherapy ensuing more favourable prognosis. Surgery is the main source of treating advanced tumors combined with post-operative chemo- and radio-therapy. Over the past two decades, the quality of life of patients with HNSCC has increased due to the ample use of more advanced surgical and radiotheraupeutic techniques, as well as organ preservation protocols. Despite these improvements, survival has not markedly improved because patients still frequently develop local-regional recurrences, distant metastases and second primary tumors. The TNM staging system, that is most often used to classify patients with HNSCC, is based on the clinical, radiological and pathological examination of tumor specimens. This system does not adequately address the molecular heterogeneity of HNSCC and the ability of staging to predict prognosis in HNSCC is limited because patients with tumours with the same clinicopathologic stage do not have the same disease progression, response to therapy, rate of disease recurrence and survival (Leemans et al, 2011; Choi \& Chen, 2005). Ongoing molecular studies show that these HNSCC may not be considered as homogenous as previously supposed (Pai \& Westra, 2009). Recognition of distinct molecular and genetic profiles could permit finer resolution of HNSCC into distinct subtypes that differ with regard to risk factors, pathogenesis and clinical behavior. A more detailed molecular 
characterization ultimately is likely to improve the development of new therapeutic strategies, potentially relevant to diagnosis and prognosis of this poorly defined subset of head and neck cancers.

\section{Risk factors}

The main risk factor for HNSCC is tobacco smoking. This risk is strongly correlated with the time and rate who person smokes. In fact, when a person stops smoking it reduces the risk of developing cancer (Schlecht et al, 1999). Besides environmental exposure to tobacco smoke, passive smoking appears to increase the risk of developing HNSCC, even for individuals who have never actively smoked (Zhang et al, 2000). This increased risk is mostly attributable to the genotoxic effects of carcinogens in tobacco smoke, including nitrosamines and polycyclic hydrocarbons. Tobacco smoking has showed to have site specific differences in the anatomical sub-regions, with an increase in sensitivity from the oral cavity down to the larynx (Werbrouck et al, 2008). Tobacco has also proven to be a significant prognostic marker (Ragin et al, 2007; Leemans et al, 2011). Identifying the molecular targets of cigarette smoking in order to discern a specific profile of tobaccoinduced mutations is still currently being studied. TP53 mutations and overexpression in HNSCC, for example, occur more frequently in patients who smoke than in patients who do not smoke (Field et al, 1991; Ronchetti et al, 2004). Much attention has been focused on genetic polymorphisms in those enzymes that activate pro-carcinogens and detoxify carcinogens; however no clear-cut association has been established yet. Heavy use of alcohol has also been recognized as an independent risk factor for HNSCC, particularly for cancer of the hypopharynx (Sturgis et al, 2004). However, alcohol consumption is mainly relevant for its ability in magnifying its effects with tobacco smoke in a synergistic manner (Talamini et al, 2002). Its ability in enhancing the effects of smoking most likely resides in its nature as a chemical solvent, increasing and prolonging mucosal exposure to the carcinogens present in tobacco (Pai \& Westra, 2009). In addition, although alcohol itself is not a direct carcinogen, its metabolites and acetaldehyde form DNA adducts that interfere with DNA synthesis and repair. Polymorphisms in the enzymes that metabolize alcohol to acetaldehyde have not been conclusively associated with modifying cancer risk. A subgroup of HNSCC, particularly those of the oropharynx and oral cavity, is also caused by high risk infection types of human papillomavirus (especially HPV-16 and 18) (Chung \& Gillison, 2009; Leemans et al, 2011). HPV has been established as a causative agent in about $70 \%$ of oral cavity and oropharyngeal cancers. The vast majority of HPV-positive HNSCC localizes to the tonsillar crypts of the lingual and palate tonsils. Its structural features render them particularly vulnerable to HPV attack (Pai \& Westra, 2009). The traditional risk factors, tobacco and alcohol use, do not appear to play a contributing role in HPV-related cancers (D'Souza et al, 2007). Certain sexual practices that facilitate repeated viral exposure are strongly associated with HPV oral infection (Smith et al, 2004). Although the risk factors for HPV viral infection are well recognized, those associated with subsequent HPV-induced tumorigenesis are now only coming into focus. However, it is known that HPV-positive and negative tumours represent different clinical pathological and molecular entities (Table 1) and that HPV-related tumours, which constitute about $20 \%$ of all HNSCC subtypes, are associated with a more favorable outcome (Chung \& Gillison, 2009, Leemans et al, 2011). 
Molecular Genetics and Biology of Head and Neck

\begin{tabular}{|l|l|l|}
\hline & HPV positive & HPV negative \\
\hline Risk factors & High-risk sexual behavior & Smoking and alcohol use \\
\hline Predilection site & $\begin{array}{l}\text { Oropharynx and oral cavity especially } \\
\text { lingual and palatine tonsil }\end{array}$ & None \\
\hline $\begin{array}{l}\text { Main molecular } \\
\text { genetic } \\
\text { alterations }\end{array}$ & $\begin{array}{l}\text { Infrequent p53 mutations, degradation of } \\
\text { p53-Rb pathway by HPV E6/E7 protein }\end{array}$ & $\begin{array}{l}\text { High frequency of p53 } \\
\text { mutations, 17p and 9p } \\
\text { loh, loss of p16 expression }\end{array}$ \\
\hline Prognosis & Better & Worse \\
\hline
\end{tabular}

Table 1. Main characteristics of HPV+ and HPV- HNSCC

\section{Genetic alterations}

It is well known that HNSCC is the result of a multistep process characterized by the accumulation of genetic and epigenetic alterations (Ha et al, 2009). The genetic alterations associated with HNSCC are numerous and include a variety of different pathways (Table 2). The accumulation and selection of these aberrant pathways may sometimes be due to random chance, but more commonly, they are attributable to a lifetime of environmental exposure to tobacco, alcohol and HPV infection. Therefore, the chance of DNA damage is high and often there is an accumulation of genetic events that lead to the development of HNSCC (Ha et al, 2009). Genetic alterations, including copy number variations (CNV), gains or losses of heterozigosity $(\mathrm{LOH})$ may cause the inactivation of tumor suppressor genes and the activation of oncogenes, which in turn lead to uncontrolled cell growth and metastasis (Chen \& Chen, 2009). In order to identify the genetic alterations, such as chromosomal deletions and/or amplifications, the presence of Single Nucleotide Polymorphisms SNPs or mutations in oncogenes/tumour suppressor genes or other genes, different techniques can be adopted from various low throughput and high throughput methods (Ha et la, 2009). The low throughput resolution methods are brought about by a study of CNV/LOH using polymerase chain reaction (PCR) -related methods and fluorescence in situ hybridization (FISH). The high throughput resolution methods are the array-related methods, such as Comparative Genomic Hybridization (CGH) array, to identify genome wide CNV/LOH events. The arrays have the ability to finely map regions of chromosomal gain or loss, much more accurately than the conventional molecular techniques. Regions of chromosomal loss commonly reported are at $1 p, 3 p, 4 p, 5 q, 8 p, 10 p, 11 q, 13 q$ and $18 q$, while those that are frequently gained are at $1 \mathrm{q}, 3 \mathrm{q}, 5 \mathrm{p}, 7 \mathrm{q}, 8 \mathrm{q}, 9 \mathrm{q}, 11 \mathrm{q}, 12 \mathrm{p}, 14 \mathrm{q}$ and $15 \mathrm{q}$ (Ha et al, 2009; Wreesmann \& Singh, 2005). Most possibly, the presence of $\mathrm{CNV} / \mathrm{LOH}$ has the potential to

\begin{tabular}{|l|l|}
\hline Locus or gene & Frequency in HNSCC \\
\hline LOH 3p & $60-70 \%$ \\
\hline LOH 9p & $70-80 \%$ \\
\hline LOH 11q & $30 \%$ \\
\hline LOH 13q & $30 \%$ \\
\hline LOH 17p & $50-70 \%$ \\
\hline p16 inactivation & $80 \%$ \\
\hline Cyclin D1 amplification & $30 \%$ \\
\hline FHIT, RASSF1A inactivation & $50-80 \%$ \\
\hline TP53 mutations & $60-80 \%$ \\
\hline
\end{tabular}

Table 2. Frequent molecular abnormalities in HNSCC (Perez-Ordonez et al, 2006) 
serve as a prognostic indicator, alone or in combination with other markers, to identify HNSCC patients at high risk of recurrence and death (Chen \& Chen, 2008).

\subsection{The molecular biology of field cancerization of HNSCC}

In 1953, the term "field cancerization" was introduced to explain two phenomena: (1) the high tendency to develop local recurrences after treatment of HNSCC and, (2) the high likelihood that multiple independent tumours would develop in the head neck mucosa (Ha \& Califano, 2003). According to this concept, molecular genetic approaches have recently shown that when a primary HNSCC is compared with a second tumour elsewhere in the respiratory tract, the paired tumours often harbor some identical patterns of genetic alterations (Pai \& Westra, 2009). In all probability, a critical genetic alteration may be a single cell providing a growth advantage over its neighboring cells. These cells can migrate to populate continuous tracts of mucosa, accumulate other alterations, acquire additional growth advantage and ultimately transform into aggressive subclones separated by time and space (Califano et al, 2000). It is important to note that, the epithelium of the upper respiratory tract may be populated by these genetically damaged clones and may lack hystopathological evidence of dysplasia. Thus, the presence of morphologically intact but genetically damaged cells may perhaps explain the mechanism underlying cancerization as well as certain distress patterns of tumour behavior, such as local recurrences following seemingly to complete surgical resection. A current model of HNSCC progression associates the loss of chromosomal arms $3 p, 9 p$ and $17 p$ with conversion from normal to dysplastic epithelium. Subsequent loss of $11 q, 13 q$ and $14 q$ is associated with progression to carcinoma in situ, with the loss of $6 p, 8 p, 8 q$ and $4 q$ seen in more advanced stages with invasive property (Califano et al, 1996; Choi \& Chen, 2005; Perez-Ordonez et al, 2006) (fig.1).

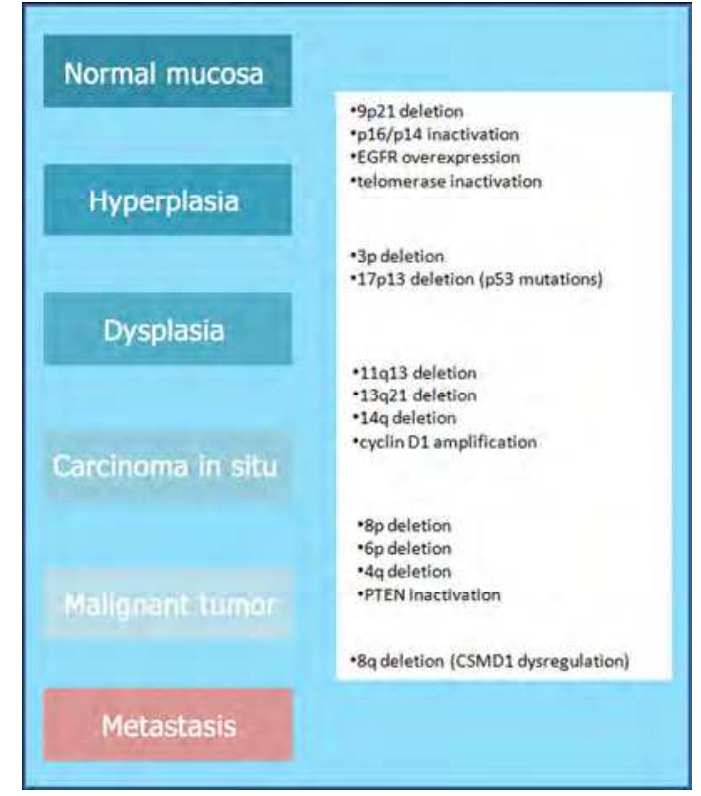

Fig. 1. HNSCC carcinogenesis model, modified from Califano et al. (1996) 


\subsection{Molecular genetics of premalignant oral lesions}

HNSCC develops from normal aereodigestive mucosa progressing through a series of histological identifiable pre-malignant stages. In particular, oral squamous cell carcinomas (OSCC) may be preceded by the appearance of lesions, which have the potential to develop into cancer in the oral cavity. The development of OSCC is generally expected upon the development of multiple, clonal, genetic alterations, which lend a clonal population of cells a growth advantage over others. The distinction between benign and potentially malignant oral lesions is currently based upon the histological examination of biopsy specimens. In the absence of a carcinoma or dysplasia, the ability to quantify the risk associated with malignant transformation is limited. It is for this reason that a molecular and genetic characterization of premalignant lesions may be very important in predicting their malignant potential. There are several histologically distinct lesions of the oral cavity that have malignant potential. These are leukoplakia, erythroplakia, lichen planus and submucous fibrosis, together with a spectrum of chromosomal, genetic and molecular alterations. The degree of similarity to OSCC found in premalignant lesions is dependent upon the presence of atypia. However, individual lesions may present molecular genetic alterations similar to OSCC, even in the absence of histologically defied dysplasia (Mithani et al, 2007).

Leukoplakia, defined as a predominantly white lesion of oral mucosa that cannot be characterized by any other definable lesion, is the most commonly diagnosed premalignant lesions in the oral cavity (Mithani et al, 2007). It is also strongly associated with the development of OSCC. Patients with oral leokoplakia have up to $36 \%$ incidence of subsequent OSCC development, only if the lesion demonstrates dysplastic features. In the absence of dysplasia, these lesions still possess a $15 \%$ incidence of cancer development (Mithani et al, 2007). In particular, increased LOH was correlated to the histopathological progression in the upper aereodigestive tract (Califano et al, 1996). 50\% of leukoplastic lesions contain allelic loss of either the $3 p$ or $9 p$ chromosome arms, which are associated with higher risk of malignant transformation. This risk increases further in the presence of additional LOH at the $4 q, 8 p, 11 q, 13 q$ and 17p loci (Rosin et al, 2000). Insertions or deletions of base pairs at microsatellites, termed microsatellite instability (MSI), are another cytogenetic feature shared between premalignant lesions and OSCC. The MSI is present in $55 \%$ of leukoplakia and there is a trend towards increasing MSI prevalence associated with histological progression of premalignant lesions (Mithani et al, 2007). In addition, many studies have demonstrated a trend in increasing polysomy at several loci, such as chromosomes 7 and 17, in the progression of the aeredigestive tract. For example, lesions with a $>3 \%$ proportion of cells with trisomy 9 have a significantly higher likelihood of progression in cancer (Lee et al, 2000; Mithani et al, 2007). It is also demonstrated that telomerase activity is correlated with the degree of atypia and dysplastic changes (Mithani et al, 2007). Finally, mitochondrial genomic mutations, which occur in response to oxidative damage and stress, may have a role in the development of cancer, including HNSCC (Sanchez-Cespedes et al, 2001). The mechanism by which these mutations contribute to carcinogenesis has not yet been demonstrated. It has been postulated to occur because of mitochondrial dysfunction in apoptosis or through reactive oxygen species generation (Gottlieb \& Tomlinson, 2005). Epigenetic changes are also important. An aberrant methylation of CpG-rich regions of the promoters prevents gene transcription by altering 
the structure of histone complex. Promoter hypermetilation is a mechanism by which tumour suppressor genes are transcriptionally inactivated (Ha \& Califano, 2006). There are few studies on the aberrant methylation occurring in leukoplakia, where the hypermetylation of RAR-b2 (Youssef et al, 2004), p16 and MGMT (Lopez et al, 2003) has been shown. These genes are metylated also in OSCC.

\subsection{Association between genetic alterations and poor outcome of HNSCC patients}

Various studies indicate that many of the $\mathrm{LOH}$ events in certain chromosomal regions are associated with shorter survival of HNSCC patients. The most commonly reported CNV and $\mathrm{LOH}$ associated with survival pertain to chromosomal regions 11q, 3q, 7p and 22q (for CNV) and in 3p, $8 p$ and 9p, 13q (for LOH) (Chen \& Chen, 2008). For example, many studies identified a consistent amplification in the head and neck tumours at region 11q13. Possibly the amplification of this region plays an important role in HNSCC survival, given the many known oncogenes, such as bcl-1, Int-2, hst-1, EMS1, CCND1 and PRAD1, in turn are correlated with clinical outcomes, that reside in this region (Chen \& Chen, 2008). As far as recurrence is concerned, the most commonly reported $\mathrm{CNV} / \mathrm{LOH}$ events associated with recurrence involved $\mathrm{CNV}$ at $11 \mathrm{q}$ and $\mathrm{LOH}$ at $9 \mathrm{p}$ and $17 \mathrm{p}$ (Chen \& Chen, 2008). Only few papers focus on the combination of histopathological and clinical characteristics, such as tumour size, lymph node status and metastasis (TNM) staging or treatment condition and the data results from $\mathrm{CNV}$ and/or $\mathrm{LOH}$ to predict survival. For example, the association between $3 \mathrm{p} \mathrm{LOH}$ and poor outcome in HNSCC patients with early stage I and II tumours was shown (Partridge et al, 1996). Other research has also shown that patients who received radiotherapy, 6q LOH was associated with reduced survival (Jamieson et al, 2003).

\subsubsection{Genetic polymorphism and their association with outcomes in HNSCC}

Single nucleotides polymorphisms (SNPs) are a DNA sequence variation occurring when a single nucleotide in the genome differs between members of a biological species or paired chromosomes in an individual. This variation in DNA sequences may not lead to an amino acid alteration and do not seem to have any adverse effects in "normal" individuals. It is possible to perform the analysis of SNPs using PCR-related methods, such as direct sequencing, or using SNP arrays. These SNPs may be markers for disease predisposition, or may be used to genetically identify patients, as they tend to cluster with ethnic background. Recent results from case-control studies of several phenotypic and genotypic assays support the hypothesis that genetic susceptibility or predisposition plays an important role in HNSCC aetiology (Negri et al, 2009; Garavello et al, 2008; Ingelman-Sundberg, 2001). It has been hypothesized that susceptibility to disease development is based on inherited differences in the efficiency of carcinogen metabolism, DNA repair and cell cycle control, or a combination of these. SNPs located in DNA repair genes can modulate DNA repair capacity and, consequently, alter cancer risk. In particular, it was shown that, among all DNA repair pathways, the sequence variations in the base excision repair (BER) pathway may contribute to HNSCC susceptibility. For example, a significantly decreased risk of HNSCC was associated with the adenosine diphosphate ribosyl transferase (ADPRT) 762Ala/Ala genotype and the combined ADPRT Val/Ala and ADPRT Ala/Ala genotypes, compared with the ADPRT Val/Val genotype (Li et al, 2007). An association between the 
presence of cytocrome P450 (CYP) and GSTs allelic variants, which are families of enzymes involved in the metabolism of many environmental agents, including tobacco and alcohol, and increased risk of HNSCC was also demonstrated. In particular, it was observed that the CYP1A2*1D variant allele confers an increased risk of HNSCC, while the CYP1A2*1C polymorphism was associated with tumour recurrence (Olivieri et al, 2009). Finally, CYP2E1*5B and GSTM1 null alleles were associated with advanced clinical stages (Olivieri, 2009). In conclusion, it is clear that genetic polymorphisms may act as predictors of risk and are also associated with tumour recurrence, since they are important for determining the parameters associated with tumour progression and poor outcomes in HNSCC. For these reasons, the identification of individuals presenting polymorphic variations would have an impact on primary prevention and early detection strategies.

\subsubsection{Genetic polymorphism and their association to tobacco and alcohol use}

Smoking and the consumption of alcohol are the main risk factors for head/neck cancer. Although the chance of developing HNSCC increases with the level of tobacco smoking and alcohol use, it is obvious that not every (heavy) smoker and/or drinker develops HNSCC. The risk for an individual to develop HNSCC after exposure to tobacco carcinogens, may therefore also depend on sequence variation in the genes (genetic polymorphisms) coding for the enzymes involved in the detoxification of tobacco smoke carcinogens, such as microsomal epoxide hydrolase (mHE), gluthatione-S-transferase (GSTs) and uridine 5'diphosphate (UDP)-glucuronosyltransferase (UGTs). Genetic polymorphisms in these genes may alter their activity and may thus modulate the risk of HNSCC. For example, the presence of null polymorphism in GSTM1 or GSTT1 was associated with an increased risk for HNSCC in smokers (Lacko et al, 2009). For the UGTs, both the variants UGT1A7 and UGT1A10 were associated with an altered risk of developing cancer (Lacko et al, 2009). Tobacco smoke is associated with the increased formation of DNA lesions, which can be repaired also by BER pathway. Therefore, also an individual variation in BER, is one of the host factors that may influence tobacco smoking-related HNSCC risk. The Rad1 c.3429 G>C polymorphism has a more evident association with cancer risk in the group of heavy smokers (Werbrouck et al, 2008). Detoxification of tobacco smoke carcinogens, together with DNA repair and apoptotic pathways, is probably the most important rescue pathways in preventing the development of tobacco-induced HNSCC. In fact, the activity of such enzymes may differ between individuals and this is one of the possible explanations for the differences in inter-individual susceptibility for the development of HNSCC.

\subsection{Epigenetic alterations}

HNSCC is a result of multiple genetic and epigenetic alterations. Epigenetic is defined as the stable inheritance of information based on gene expression levels without changing the underlying genetic code (Esteller et al, 2002). These heritable modifications of the DNA molecule itself occur through several pathways including alterations in DNA methylation and histone modifications mediated by: DNA methyltransferases (DNMT), methyl-CpGbinding domain proteins, histoneacethyltranferases (HAT), histone deacetylases (HDAC), histone methyltransferases (HMT) and histone demethylases (Glazer et al, 2009). Epigenetic changes have been associated with cancer specific expression differences in human 
malignancies, including HNSCC (Herman et al, 2003). These alterations are known to occur early in tumoriginesis and are associated with distinctive cancer types. The main epigenetic modification found in humans is the methylation of the $5^{\prime}$ carbon of the cytosine ring within cytosine-guanine dinucleotides (CpGs) by the enzyme class methyltransferases. CpG methylation occurs in patterns both species and tissue specific, serving to block transcription and recruit histone and modifying tightly packed heterochromatin and gene silencing. DNMTs are responsible for maintaining the methylation status of a gene in the cell's progeny. In addition, histone modification has also been shown to play an active role in regulating gene expression. Histone modifications and DNA methylations play a significant role in the organization of nuclear structure, ultimately influencing gene expression. The epigenetic inactivation of tumor suppressor genes is an important event in HNSCC (Steinmann et al, 2009; Glazer et al, 2009). In recent years, new assays, such as sodium bisolfite treatment of DNA, which converts the non-methylated cytosines to uracyl, and methylation sensitive quantitative PCR, have further advanced the ability to evaluate the methylation status of tissue samples. In HNSCC, the promoter hypermethylation of p16 is a frequent event (Reed et al, 1996; Glazer et al, 2009; Steinmann et al, 2009). Studies on promoter methylation have uncovered many other genes in HNSCC, such as DIM-6, ATM, p15, TIMP-3, MGMT, RARB-2, DAP-K, E-cadherin, Cyclin A1, RASSF1A, CDKN2A, CDH1 and DCC (Steinmann et al, 2009). These genes are involved in pathways that control cell cycle progression, apoptosis, cell-cell adhesion, DNA repair and tumour invasion. A trend toward an increased methylation of these genes in more advanced tumour stages and less differentiated HNSCC was observed. In particular, p16 methylation was significantly high in poorly differentiated HNSCC and RASSF5 methylation occurred preferentially in advanced tumour stages, while methylation of RASSF4 was higher in patients with recurrence (Steinmann et al, 2009). A relationship between methylation profiling, tumour stage and age of patients was also shown (Marsit et al, 2009). A borderline significant association between tumour site and methylation pattern was also observed (Marsit et al, 2009). These data reveal that patterns of epigenetic alteration may hold a relevant role in identifying the process through which carcinogens act epigenetically to drive tumourigenesis as well as in providing useful tools with diagnostic value.

\subsubsection{Epigenetic alterations and correlation with aetiologic agents and clinical parameters}

DNA methylation-associated epigenetic silencing of tumor suppressor genes is an aberrant marker of cancer with considerable specificity. An association among HPV, tobacco smoking and alcohol exposure and methylation of specific genes has been identified. In particular, using a whole genome profiling approach, not only was there a correlation between methylation and tobacco and alcohol use, but also in considering smoking intensity (packs per day) and lifetime average drinks per week (Marsit et al, 2009). Tumour HPV16 DNA status also demonstrated to have an association with methylation, showing that HPV+ and HPV- HNSCC patients do not only have a different pattern of methylation, but have a more pronounced hypomethylation in HPV-negative tumours than in HPV-positive tumours (Richards et al, 2009). In addition, genomic instability, as measured by genome-wide loss of heterozogosity ( $\mathrm{LOH}$ ) and single nucleotide polymorphism (SNP) analysis, is greater in HNSCC samples with more pronounced hypomethylation. For example, epigenetic 
inactivation of the SFRP genes is associated with drinking, smoking and HPV. Promoter methylation of SFRP1 occurred more often in both heavy and light drinkers compared to non drinkers. SFRP4 promoter methylation, on the other hand, occurred at a higher prevalence in never smokers and former smokers than in current smokers, and also was independently associated with HPV16 viral DNA (Marsit et al, 2006).

\section{Potential molecular prognosis markers in HNSCC}

HNSCC has long been a challenge in regards to treatment because of the high rate of recurrences and advanced diseases at the time of diagnosis. Molecular identification of tissue biomarkers in diagnostic biopsy specimens may not only identify patients at risk for developing HNSCC but also select patients that may benefit from more aggressive treatment methods. In addition, they may potentially offer new methods for early diagnosis, monitoring and treatment alternatives for HNSCC patients. Some emerging molecular markers include TP53, epidermal growth factor receptor (EGFR), cyclin D1, transforming growth factor alpha (TGF-alfa), p16 INK4A, cyclooxigenase-2 (Cox-2), vascular endothelial growth factor (VEGF) and matrix metallo proteinases (MMPs) (Table 3).

\begin{tabular}{|c|c|c|c|c|}
\hline $\begin{array}{l}\text { Molecule } \\
\text { name }\end{array}$ & $\begin{array}{l}\text { Genomic } \\
\text { localization }\end{array}$ & Function & From literature & References \\
\hline TP53 & 17 p13 & $\begin{array}{l}\text { A tumor- } \\
\text { suppressor } \\
\text { regulating cell } \\
\text { cycle } \\
\text { progression, } \\
\text { apoptosis and } \\
\text { cell survival }\end{array}$ & $\begin{array}{l}\text { shows TP53 somatic } \\
\text { mutations causing mostly } \\
\text { p53 protein } \\
\text { overexpression. } \\
\text { prognostic value for } \\
\text { survival, recurrence, } \\
\text { treatments response and } \\
\text { lymph node status }\end{array}$ & $\begin{array}{l}\text { - Bradford et al, } 2003 \\
\text { - Cabanillas et al, } 2007 \\
\text { - Cabelguenne et al, } 2000 \\
\text { - Gasco and Crook, } 2003 \\
\text { - Graveland et al, } 2011 \\
\text { - Lassaletta et al, } 1999 \\
\text { - Leemans et al, } 2011 \\
\text { - Nees et al,1993 } \\
\text { - Nogueria et al, } 1998 \\
\text { - Nylander et al, } 2000 \\
\text { - Perrone et al, } 2010 \\
\text { - Poeta et al, 2007 } \\
\text { - Quon et al, 2001 } \\
\text { - Temam et al, } 2000 \\
\text { - Thomas et al, } 2005\end{array}$ \\
\hline $\begin{array}{l}\text { p16 }{ }^{\mathrm{INK} 4 \mathrm{~A}} \\
(\mathrm{CDKN} 2 \mathrm{~A})\end{array}$ & $9 p 21$ & $\begin{array}{l}\text { A tumor- } \\
\text { suppressor } \\
\text { regulating } \\
\text { senescence and } \\
\text { cell-cycle } \\
\text { progression by } \\
\text { acting as an } \\
\text { inhibitor of } \\
\text { cyclin dependent } \\
\text { kinase } 4 \text { and 6- } \\
\text { cyclin D } \\
\text { complexes }\end{array}$ & $\begin{array}{l}\quad 50-80 \% \text { of HNSCC } \\
\text { shows loss of p16 } \\
\text { expression, mostly by } \\
\text { promoter } \\
\text { hypermethylation or } \\
\text { homozygous deletion. } \\
>\quad \text { Prognostic value } \\
\text { for survival and } \\
\text { development of distant } \\
\text { metastases } \\
>\quad \text { High p16 } \\
\text { expression in combination } \\
\text { with persistent HPV16-18 } \\
\text { infection predicts a better } \\
\text { prognosis }\end{array}$ & $\begin{array}{l}\text { - Ambrosch et al, } 2001 \\
\text { - Bazan et al, } 2002 \\
\text { - Broek et al, 2009 } \\
\text { - Thomas et al, } 2005 \\
\text { - Namazie et al, } 2002 \\
\text { - Thomas et al, } 2005 \\
\text { - Yuen et al, } 2002\end{array}$ \\
\hline
\end{tabular}




\begin{tabular}{|c|c|c|c|c|}
\hline $\begin{array}{l}\text { Molecule } \\
\text { name }\end{array}$ & $\begin{array}{l}\text { Genomic } \\
\text { localization }\end{array}$ & Function & From literature & References \\
\hline PTEN & $10 \mathrm{q} 23$ & \begin{tabular}{|l|} 
A tumor \\
suppressor gene \\
regulating \\
signaling \\
pathways \\
controlling cell \\
proliferation and \\
apoptosis
\end{tabular} & $\begin{array}{l}\text { shows loss of PTEN } \\
\text { show } \\
\text { prognostic value in } \\
\text { relation to poor outcome. } \\
\text { between PTEN } \\
\text { overexpression and } \\
\text { increase of radioresistance }\end{array}$ & $\begin{array}{l}\text { - Mriouah et al, } 2010 \\
\text { - Pai and Westra, } 2009 \\
\text { - Pattje et al, 2010 } \\
\text { - Pedrero et al, } 2005\end{array}$ \\
\hline Cyclin D1 & $11 q 13$ & $\begin{array}{l}\text { Proto-oncogene } \\
\text { regulating cell } \\
\text { cycle progression }\end{array}$ & $\begin{array}{l}\quad 17-79 \% \text { of } \mathrm{HNSCC} \\
\text { shows amplification and } \\
\text { overexpression of cyclin } \\
\text { D1 } \\
\text { relation to more advanced, } \\
\text { aggressive disease, lymph } \\
\text { node metastasis and } \\
\text { reduced survival }\end{array}$ & $\begin{array}{l}\text { - Akervall et al, } 1997 \\
\text { - Capaccio et al, } 2000 \\
\text { - Holley et al, } 2005 \\
\text { - Kumar et al, } 2003 \\
\text { - Leemans et al, } 2011 \\
\text { - Marsit et al, 2008 } \\
\text { - Michalides et al, } 1997 \\
\text { - Namazie et el, } 2002 \\
\text { - Nimeus et al, } 2004 \\
\text { - Okami et al, } 1999 \\
\text { - Pyeon et al, 2007 } \\
\text { - Thomas et al, } 2005 \\
\text { - Volavsek et al, } 2003\end{array}$ \\
\hline EGFR & $7 \mathrm{p} 11$ & $\begin{array}{l}\text { Trans membrane } \\
\text { TK acting as a } \\
\text { central } \\
\text { transducer in } \\
\text { multiple } \\
\text { pathways that } \\
\text { mediate cell } \\
\text { cycle } \\
\text { progression, } \\
\text { angiogenesis, } \\
\text { inhibition of } \\
\text { apoptosis, tumor } \\
\text { invasion and } \\
\text { metastasis }\end{array}$ & $\begin{array}{l}>34-90 \% \text { of HNSCC } \\
\text { shows overexpression of } \\
\text { EGFR } \\
>\quad \text { Prognostic value in } \\
\text { relation to disease free } \\
\text { survival and overall } \\
\text { survival; association with } \\
\text { a shorter overall survival } \\
\text { and poor outcomes. } \\
>\quad \text { From } 2006 \text { use of } \\
\text { therapy based on EGFR } \\
\text { inhibitors }\end{array}$ & $\begin{array}{l}\text { - Carracedo et al, } 2008 \\
\text { - Chang et Califano, } 2008 \\
\text { - Hama et al, } 2009 \\
\text { - Kalyankrishna and } \\
\text { Grandis, 2006 } \\
\text { - Quon et al, } 2001 \\
\text { - Smilek et al, } 2006 \\
\text { - Uribe \& Gonzalez, } 2011\end{array}$ \\
\hline VEGFs & & $\begin{array}{l}\text { Ligands of trans } \\
\text { membrane TK } \\
\text { promoting cell } \\
\text { proliferation, } \\
\text { migration and } \\
\text { survival of } \\
\text { endothelial cells } \\
\text { during tumor } \\
\text { growth }\end{array}$ & $\begin{array}{l}\text { } 90 \% \text { of HNSCC } \\
\text { shows overexpression of } \\
\text { VEGFs (especially A and C } \\
\text { forms), } \\
\text { pro-angiogenic factors, } \\
\text { which promote } \\
\text { neovascularization in } \\
\text { cancer. } \\
>\quad \text { They are associated } \\
\text { with tumor growth, } \\
\text { metastasis, treatment } \\
\text { failure and shorter overall } \\
\text { survival }\end{array}$ & $\begin{array}{l}\text { - Kyzas et al, } 2004 \\
\text { - Kyzas et al, } 2005 \\
\text { - Lentsch et al, } 2006 \\
\text { - Mineta et al, } 2000 \\
\text { - Moryama et al, } 1997 \\
\text { - Neuchrist et al, } 2001 \\
\text { - Neuchrist et al, } 2003 \\
\text { - Petruzzelli et al, } 1997\end{array}$ \\
\hline
\end{tabular}




\begin{tabular}{|c|c|c|c|c|}
\hline $\begin{array}{l}\text { Molecule } \\
\text { name }\end{array}$ & $\begin{array}{l}\text { Genomic } \\
\text { localization }\end{array}$ & Function & From literature & References \\
\hline Cox2 & 1q25.2-25.3 & $\begin{array}{l}\text { Catalytic enzyme } \\
\text { decreasing } \\
\text { apoptosis, } \\
\text { increasing } \\
\text { inflammation } \\
\text { and important } \\
\text { for tumor } \\
\text { progression }\end{array}$ & $\begin{array}{l}\text { Presence of Cox } 2 \\
\text { up regulation in tumor } \\
\text { (150 folds) and adjacent } \\
\text { tissues ( } 50 \text { folds) } \\
\text { compared to nomal } \\
\text { epithelium. } \\
>\quad \text { It seem to be an } \\
\text { early event in HNSCC } \\
\text { carcinogenesis } \\
>\quad \text { Prognostic value } \\
\text { for survival; Cox } 2 \\
\text { overexpression in } \\
\text { combination with PEG } 2 \text { is } \\
\text { associated with a shorter } \\
\text { overall survival } \\
>\quad \text { Prognostic marker } \\
\text { in premalignant lesions. } \\
>\quad \text { Low levels of Cox } \\
2 \text { are associated with } \\
\text { poorer overall survival in } \\
\text { larynx cancer } \\
>\quad \text { Independent } \\
\text { predictor of disease-free } \\
\text { survival. } \\
>\quad \text { Ongoing } \\
\text { preclinical studies with } \\
\text { therapy based on Cox-2 } \\
\text { inhibitors in combination } \\
\text { with EGFR inhibitors }\end{array}$ & $\begin{array}{l}\text { - Gallo et al, } 2002 \\
\text { - Itoh et al, } 2003 \\
\text { - Ranelletti et al, } 2001 \\
\text { - Sudbo et al, } 2003 \\
\text { - Thomas et al, } 2005\end{array}$ \\
\hline TGF alfa & $2 \mathrm{p} 13$ & $\begin{array}{l}\text { Growth factor } \\
\text { inducing } \\
\text { epithelial } \\
\text { development } \\
\text { and primary } \\
\text { ligand of the } \\
\text { EGFR }\end{array}$ & $\begin{array}{l}\text { Association } \\
\text { between TGFA } \\
\text { overexpression and poor } \\
\text { outcome and response to } \\
\text { anti-EGFR therapy }\end{array}$ & $\begin{array}{l}\text { - Logullo et al, } 2003 \\
\text { - Quon et al, } 2001 \\
\text { - White et al, } 2010\end{array}$ \\
\hline MMPs & & $\begin{array}{l}\text { Family of Zn- } \\
\text { dependent } \\
\text { proteolytic } \\
\text { enzymes that } \\
\text { degrade the } \\
\text { basement } \\
\text { membrane and } \\
\text { other } \\
\text { components of } \\
\text { the extracellular } \\
\text { matrix }\end{array}$ & $\begin{array}{l}>\quad \text { Overexpression in } \\
\text { HNSCC of various MMPs, } \\
\text { including MMP2, MMP8, } \\
\text { MMP13 Association with } \\
>\quad \text { poor outcome, cisplatin } \\
\text { resistance, lymph node } \\
\text { metastasis and early } \\
\text { recurrence. } \\
>\quad \text { Evidences about } \\
\text { association between the } \\
\text { EGFR signaling and } \\
\text { MMPs activation }\end{array}$ & $\begin{array}{l}\text { - Kusukawa et al, } 1996 \\
\text { - O-Charoenrat et al, } 2000 \\
\text { - Patel et al, } 2005 \\
\text { - Sinpitaksakul et al, } 2008 \\
\text { - Thomas et al, } 2005\end{array}$ \\
\hline
\end{tabular}

Table 3. Biomarkers in head and neck cancers 


\subsection{TP53}

TP53 is a tumour suppressor gene located on chromosome $17 \mathrm{p} 13$ and consists of 11 exons that encode protein p53, and functions in carcinogenesis by initiating G1 arrest in response to certain DNA damage and apoptosis. Studies suggest that after mutation in one TP53 allele, the remaining wild type (w.t.) allele is often deleted and therefore the mutant phenotype is expressed (Yin et al, 1993; Kiuru et al, 1997). The prevalence of TP53 mutations is $20-70 \%$ in HNSCC (Blons et al, 2003). The reported frequency of the mutations varies among different studies. This is related, at least in part, to techniques used for detecting mutations, the regions of the TP53 gene analyzed, and the anatomic site of the analyzed sample tumours. Exons 5 to 8 (encoding the "core" domain) of TP53 are the most analyzed because they represent the major site of TP53 mutations. However, other studies report that a considerable amount of HNSCC carries TP53 mutations outside the core domain of p53 (Balz et al, 2003; Saunders et al, 1999).

\subsubsection{Tobacco and TP53}

An explanation for the heterogeneity of TP53 mutation frequency could be the different levels of exposure to risk factors in the population studied. In fact, the frequency of TP53 mutation in patients with invasive HNSCC was related to the level of exposure to cigarette smoke and alcohol (Blons et al, 2003; Ronchetti et al, 2004; Hussain et al, 1999). The frequency of somatic TP53 mutation in smoking HNSCC patients was at least double compared to non-smoking HNSCC patients (Field et al, 1991). DNA can be damaged by numerous tobacco carcinogens and environmental chemicals that can be activated or degraded by specific enzymes termed xenobiotic-matabolizing enzymes (XMEs). The existence of XMEs variants may explain individual susceptibility to TP53 mutations. An $\mathrm{XME}$ genotype that results in increased DNA damage as a consequence of altered carcinogen metabolism could increase the incidence of TP53 mutations (Blons et al, 2003). For example, a strong association between TP53 mutation and CYP1B1 genotypes was found in smokers (Ko et al, 2001; Thier et al, 2002). Finally, an increased sensitivity to mutagens as a result of low DNA repair capacity increases the frequency or modify the pattern of TP53 mutations (Casse et al, 2003; Wong et al, 2002). As expected from experimental tobacco carcinogenesis, the most prevalent mutations in HNSCC are G:C>A:T transitions and $\mathrm{G}: \mathrm{C}>\mathrm{T}: \mathrm{A}$ tranversions. It is also interesting to note that frameshift mutations, which are more frequent in patients exposed to both alcohol and tobacco, occur more frequently in HNSCC than in other tobacco-independent cancer types (Blons et al, 2003).

\subsubsection{Is TP53 mutation an early or a late event?}

The expression of the p53 protein has been detected also in oral premalignant lesions (such as leukoplakia), where it may indicate an impending malignancy. Specifically, suprabasal expression has been highly predictive of malignant development (Cruz et al, 1998). In addition, when surgical margins of primary HNSCC are examined for mutational changes, there is an increased risk of local recurrence when positive margins demonstrating clonal alterations in TP53 are observed (Graveland et al, 2011). However, there have been conflicting conclusions concerning the stage at which TP53 mutations occur during HNSCC carcinogenesis. Early studies performed by immunocytochemistry suggested that TP53 alterations are an early event in the carcinogenesis of HNSCC. In contrast, subsequent 
studies have found that TP53 mutations represent a late event and are associated with an invasive phenotype (Shahnavaz et al, 2000; Shin et al, 2000). Whether this is due to different methods in the evaluation of TP53 mutations or whether they define new subgroups in the HNSCC is still an open question. As described, TP53 mutations are frequently detected by immunohistochemical analysis. This simple analysis is based on the finding that mutant p53 protein, adopting an altered conformation, becomes very stable, facilitating its detection and allowing its use as a marker for gene mutation. However, not all types of mutations are detected by this method, because some of them do not lead to protein stabilization. It is possible that some TP53 mutations result in negative immunostaining or wild type TP53 gene may be associated with p53 protein overexpression (Strano et al, 2007). Consequently, direct sequencing of the TP53 gene is probably the most important component for any TP53 evaluation at present.

\subsubsection{Clinical evaluation of TP53 status}

When the mutational analysis of TP53 and the clinical outcome in patients with HNSCC as a whole are correlated, studies have reported contradictory results even when using the same molecular techniques. The correlation between p53 expression and clinical outcome in patients with HNSCC, however, has been questioned (Thomas et al, 2005) (Table 3). A number of studies have shown that TP53 gene mutations are associated with an increased risk for locoregional recurrence and poor outcome (Thomas et al, 2005). Furthermore, a significant correlation between p53 expression and clinical outcome appears to be strongest in the subgroup of patients with laryngeal SCC (Narayana et al, 1998; Nylander et al, 2000). Although there are many studies correlating mutations or overexpression of p53 with poor outcomes, others have shown that TP53 mutations or overexpression do not independently predict clinical outcomes in patients with HNSCC (Thomas et al, 2005). Possible explanations for incongruity between these studies may be due to a failure of immunohistochemical techniques to detect actual TP53 mutations, differences between races, variation in tissue handling and analysis techniques and variation in the definition of overexpression (Strano et al, 2007(b); Thomas et al, 2005). In addition, differences observed in the impact of TP53 alterations on prognosis may be due to different treatment methods. In fact, a predictive role of TP53 mutations on treatment responses, in particular in radiotherapy and chemotherapy, was demonstrated (Blons et al, 2003). Furthermore, in the TP53 mutations located in the DNA binding domain, the chance of a major response to chemotherapy treatments were inferior. Finally, the accumulation of mutant p53 protein leads to the production of anti-p53 antibodies. Their presence is significantly correlated with increased risks of recurrence and death (Blons et al, 2003).

\subsubsection{Therapy by reactivation or elimination of mutant p53 protein}

HNSCC has been one of the first tumour localities to benefit from gene transfer therapy. The transfection of wild type TP53 into cell lines induced growth arrest and reduced tumourigenicity in nude mice. This suggested that restoring p53 function in HNSCC could inhibit cell growth (Strano et al, 2007(b)). Therapeutic strategies based on p53 tumour suppressor function were initiated. One of these approaches is based on the functional correction of mutant p53 protein using short synthetic peptides derived from the C-terminus of wt-p53. In particular, these peptides can increase the DNA binding ability of wt-p53 and 
restore the transcriptional activity of some gain of function mutants. This application is severely restricted by the complexity of the synthesis, stability limitations, restricted uptake and intracellular processing. Stabilizing the native form of p53 protein (correctly folded) by shifting the equilibrium from its denatured form was another idea. As a consequence of the re-acquired native folding, some p53 mutants are able to activate wt-p53 target genes and promote apoptosis (Strano et al, 2007(b)). Finally, the last therapeutic strategy is based on the elimination of mutant p53. The efficient replication of adenovirus requires the neutralization of p53 function through E1B viral protein. ONYX-015 is an engineered adenovirus that does not express E1B protein and consequently is unable to inactivate p53. The infection of tumour cells carrying TP53 mutations with ONYX-15 provokes apoptosis. Clinical trials are underway in HNSCC patients. While the treatment with ONYX-15 alone gave only marginal effects, its combination with cisplatin and 5-fluorouracil had a more profound impact on the response of patients (Strano et al, 2007(b)); Perrone et al, 2010).

\subsubsection{Oncogenic properties: Gain of function of mutant p53}

Mutant p53 proteins are unable to transcriptionally regulate wt-p53 target genes and to exert its antitumoral effects such as apoptosis, growth arrest, differentiation and senescence. On the other hand, countless evidence has demonstrated that at least certain mutant forms of the p53 protein may possess gain of function activity, thereby positively contributing to the development, maintenance and spreading of many types of tumours, including HNSCC (Gasco \& Crook, 2003; Strano et al, 2007(a)). A great amount of in vitro and in vivo evidence have firmly established an oncogenic role of certain missense TP53 mutations (such as p53R175H), located especially in the DNA binding domain (Strano et al, 2007). The resulting protein is a full-length protein, with a single aminoacid change that is sufficient to make them unable to recognize the wt-TP53-DNA consensus on target gene promoters. In addition, the half-life of mutant p53 protein is extremely prolonged compared to that of w.t.p53. It has been hypothesized that mutant p53 proteins could serve as oncogenic transcription factors. By genome-wide expression profile techniques it has been shown that p53 mutant proteins can modulate sets of genes involved in oncogenic activities (Strano et al, 2007). Furthermore, the semiquantitative SnaPshot analysis in HNSCC TP53 mutant patients shows a higher expression of missense mutant allele compared to w.t. These data demonstrate that TP53 missense and nonsense mutations have a dissimilar allelic expression imbalance (AEI) behavior in HNSCC, mostly likely independent from the LOH TP53 status. The positive AEI in favour of TP53 missense mutations could be due to the inactivation of w.t. allele, as well as to the higher expression or mRNA stability of mutant allele (Ganci et al, 2011). Comparatively, the low expression of the nonsense mutations compared to the w.t. allele in HNSCC tissue may be due to the nonsense mediated decay (MND) surveillance pathway, which ensures the rapid degradation of the mRNAs containing premature translation termination codons (Behm-Ansmant et al, 2007).

\subsection{6 p53 as a marker for the clonal heterogeneity identification of tumor cells}

The most striking features of HNSCC are its histopatological heterogeneity and the disparity between biological behavior, which is extremely variable, and morphological classification. It is well recognized that patients with similar stages of head and neck cancer may have a diverse clinical course and response to similar treatment (Kearsley et al, 1990). Considerable 
intratumor heterogeneity for genetic alterations has been demonstrated, as shown in the genetic analysis by LOH and MSI on chromosomes 17p13 (p53) and 9p21 (RPS6) (Wang et al, 2006). They examined the differential genetic composition of the histological high-grade and low-grade areas showing an increase of aberration proportions for both loci in the poorly differentiated region of the tumour. Similar results were obtained by the immunohistochemistry (IHC) analysis of mutant p53 staining from hematoxylin and eosin HNSCC sections (Ganci et al, 2011; Wang et al, 2006; Boyle et al, 1993). A higher number of p53 positive cells were observed in poorly differentiated regions than in moderately or well differentiated ones (fig.2). Furthermore, data from cloning and sequencing p53 cDNA in tumours carrying double and triple p53 mutations showed that different p53 mutated alleles were present (Ganci et al, 2011). On the other hand, HNSCC tissues carrying double/triple p53 mutations on different alleles showed a positive, but not homogenous p53 staining, independently from the state of tumour cell differentiation, probably relying on the presence of clonal populations carrying different TP53 mutations in the same tumour (Ganci et al, 2011) (fig.2). The intratumour heterogeneity, which was also demonstrated for the methylation status (Varley et al, 2009), could be due to multiple different processes of carcinogenesis, where clonal populations arising within tumours may undergo separate individual genetic changes conferring different aggressiveness capacity.

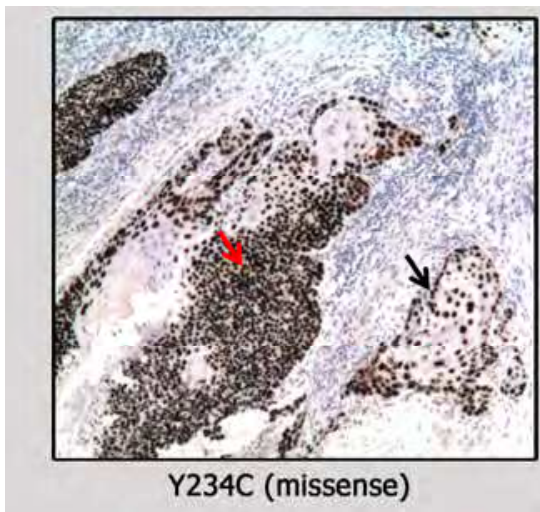

(a)

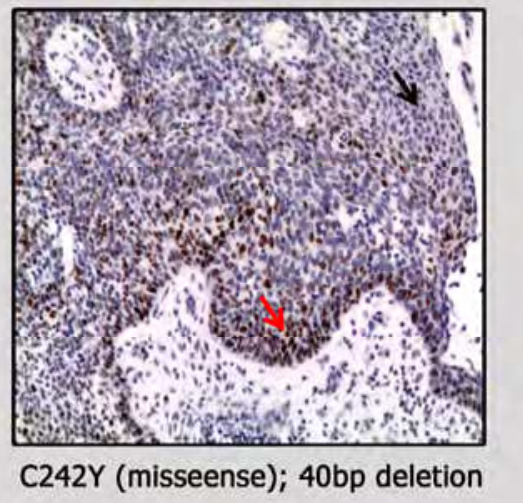

(b)

(a) p53 Y234C protein shows positive staining by IHC. A higher number of p53 positive cells was observed in poorly differentiated (red arrow) tissue areas than in moderately or well differentiated ones (black arrow). (b) The tissue carrying the two TP53 mutations C242Y and Del.T155-M169 (deletion of $40 \mathrm{bp}$ ) on separate alleles shows overexpression of p53 protein. A positive, but not homogeneous, p53 staining was observed by IHC independently from the tumor cell differentiation state, probably relying on the presence of clonal populations carrying different TP53 mutations in this tumor. Red and black arrows indicate regions with positive and negative p53 staining, respectively, in a poorly differentiated tumor area.

Fig. 2. p53 as a marker for the clonal heterogeneity in HNSCC

\subsubsection{HPV infection and correlation with p53 status}

Similar to tobacco and alcohol use, oral human papilloma virus (HPV) infection, plays a role in the pathogenesis of HNSCC. The transforming potential of high-risk, oncogenic types (as 
HPV-16, 18), is largely a result of the function of two viral proteins, E6 and E7, which functionally inactivate two human tumour suppressor proteins, p53 and pRB, respectively. Expression of high-risk HPV E6 and E7 results in cellular proliferation, loss of cell cycle regulation, impaired cellular differentiation, increased frequency of spontaneous and mutagen-induced mutations and chromosomal instability (Chung \& Gillison, 2009) (fig. 3). HPV was detected in about $20 \%$ of HNSCC cases especially in oropharynx and oral cancer (Leemans et al, 2011; Rosenquist et al, 2007). The possible involvement of TP53 status and HPV infection was suggested by several studies in which HPV DNA was detected and almost all positive cases were w.t. for TP53 (fig. 4) (Smith et al, 2010; Mitra et al, 2007). HPV positive cancer was also associated with a significantly better prognosis than HPV negative cases, which have a higher frequency of TP53 mutations. Altogether, these data support the evidence that HPV positive HNSCC is a distinct pathobiological and clinical disease component (Leemans et al, 2011).

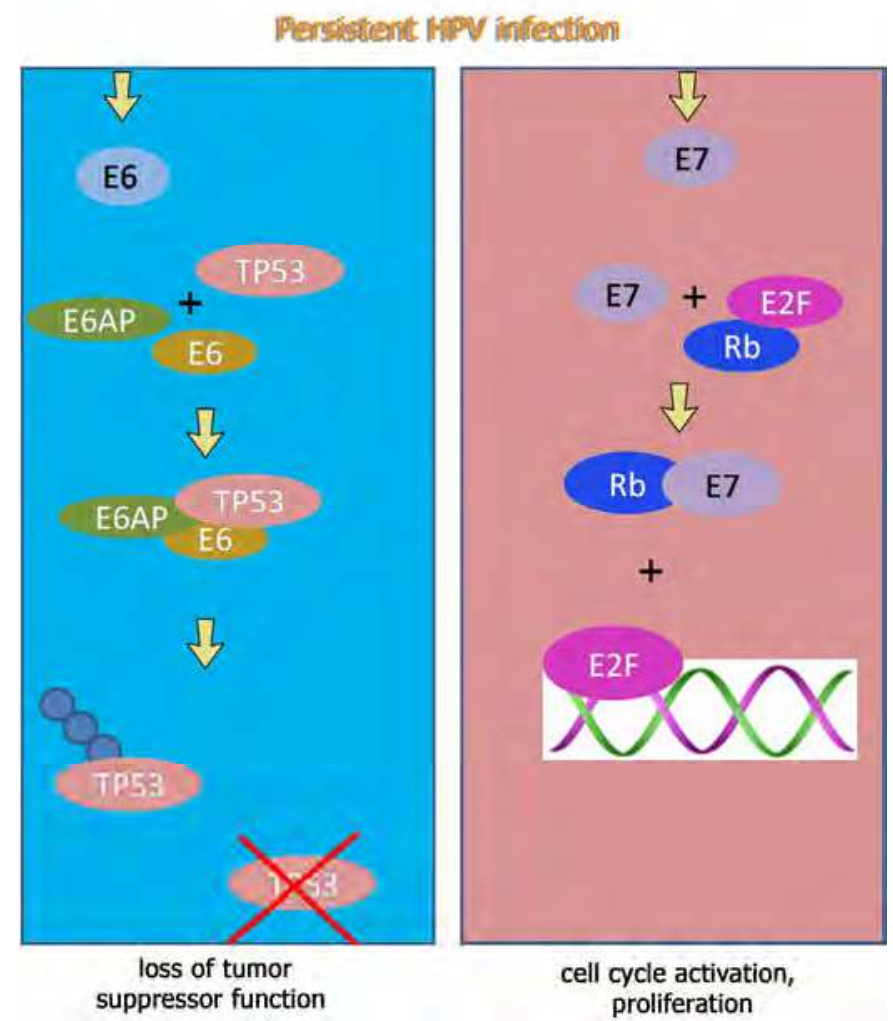

The human papillomavirus (HPV) genome contains various early and late open reading frames and encodes two viral oncoproteins: E6 and E7. The E6 protein binds p53 and targets the protein for degradation (by ubiquitination), whereas the $\mathrm{E} 7$ protein binds and inactivates the Rb pocket proteins. The molecular consequence of the expression of these viral oncoproteins is cell cycle entry and inhibition of p53-mediated apoptosis, which allows the virus to replicate $\mathrm{E} 6 \mathrm{AP}=\mathrm{E} 6$ adaptor protein.

Fig. 3. HPV infection affects cell cycle. 


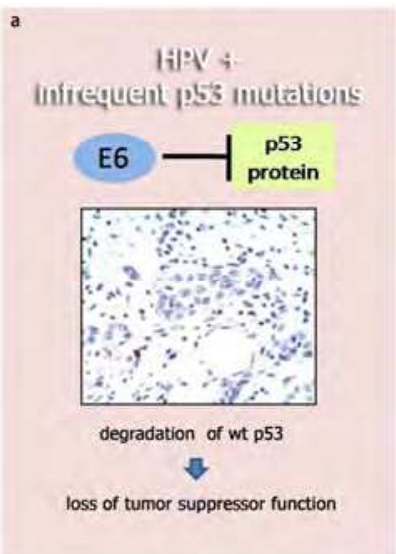

a)

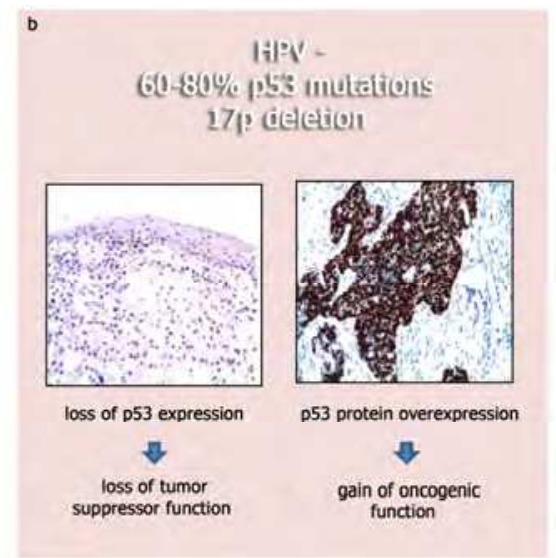

b)

a) In HPV + HNSCC the oncoprotein HPV E6 promotes p53 degradation. Consequently p53 protein expression is not detected in the tumor by IHC. p53 inactivation by HPV causes loss of its tumor suppressor function.

b) In HPV- HNSCC, p53 tumor suppressor function is mainly inactivated by $17 \mathrm{p} 13$ deletion and/or TP53 mutations. A subset of TP53 mutations, mainly missense mutations, show not only loss of tumor suppressor properties, but also gain of oncogenic functions. These mutations are often associated with p53 protein overexpression by IHC.

Fig. 4. Correlation of TP53 status and HPV infection in HNSCC

\subsubsection{P72R TP53 polymorphism}

A common polymorphism exists in exon 4 of the TP53 gene resulting in the expression of either arginine $(\mathrm{R})$ or proline $(\mathrm{P})$ at codon 72 (Matlashewski et al, 1987). This sites is within the apoptosis-signalling domain of the protein. The $\mathrm{R}$ form of w.t. p53 is more leading to the hypothesis that individuals homozygous for $\mathrm{R}$ in the germ-line are at higher risk of HPV associated cancers than carriers of other genotypes (Storey et al, 1998). Several studies have addressed this possibility in HNSCC, but none have identified an increased frequency of any codon 72 genotype. Despite the apparent absence in the association between codon 72 genotype and risk of HNSCC, there is evidence demonstrating that the clinico-pathological characteristics of cancers may be affected by polymorphism (Gasco \& Crook, 2003). Loss of the $72 \mathrm{P}$ allele has been reported in several studies. In a small series of HNSCC from northern Europe and Japan, there was a clear bias for TP53 mutants to target the 72R allele and for $\mathrm{LOH}$ to involve the $72 \mathrm{P}$. $72 \mathrm{R}$ mutants more potently inhibit $\mathrm{p} 73$, a protein belonging to the p53 family, than equivalent $72 \mathrm{P}$ mutants. It is a persuasive possibility that preferential retention of 72R mutants in HNSCC is a reflection of this activity (Gasco \& Crook, 2003). The study of the effect of this polymorphism on clinical outcomes of HNSCC will be of great interest.

\subsection{Other potential molecular prognostic markers}

EGFR is a transmembrane tyrosine kinase capable of promoting neoplastic transformation. Binding to the extracellular domain of EGFR causes the activation of a number of 
downstream effectors including the activation of tyrosine kinase and activation of intracellular Ras, Raf and mitogen-activated protein kinase cascades. They are involved in malignant transformation and tumour growth through the inhibition of apoptosis, cellular proliferation, promotion of angiogenesis and metastasis. The EGFR family includes EGFR, cerbB2, c-erbB3 and c-erbB4, which have the ability to form receptor heterodimers and crosstalk between them. Both EGF and the transforming growth factor (TGF)-alpha are ligands that bind to EGFR (Thomas et al, 2005; Kalyanrshna \& Grandis, 2006). EGFR expression has been extensively studied in HNSCC and its overexpression reported in 34$80 \%$ of HNSCC using IHC (Beckhardt et al, 1995; Grandis et al, 1993). However, EGFR expression may occur in two stages, the over-expression in normal and well-differentiated epithelia adjacent to the tumour and the upregulation from dysplasia to HNSCC that may result from gene amplification. This marker has been significantly associated with short disease-free survival, overall survival and poor prognosis in HNSCC patients (Table 3). Data showing an increased expression of EGFR in well and moderately differentiated tumour cells and in dysplastic tissue compared with poorly differentiated tissue, suggest that EGFR upregulation may be an early event during HNSCC carcinogenesis. Co-expression of Her2 and Her3, which do not have intrinsic tyrosine kinase activity, is reported to increase transforming activity, and their expression has been strongly associated with shortened patient survival (Thomas et al, 2005). EGFR over-expression has been shown to be an independent prognostic factor for neck node relapse in primary specimens of patients with laryngeal cancer (Almadori et al, 1999). Increased tumour resistance to cytotoxic agents, including radiotherapy has been associated with EGFR over-expression in HNSCC, in addition to its association with more aggressive tumour behavior (Thomas et al, 2005). This suggests that the evaluation of EGFR status at the time of diagnosis may help identify subsets of patients, who are at increased risk of neck node metastasis, may have an unfavorable radiotherapy treatment outcome and may therefore benefit from more aggressive treatments. Several studies, however, have found no association between EGFR and clinical stage, including lymph node status, extracapsular invasion, recurrence or survival in specimens from HNSCC patients using IHC, Western or Southern blot techniques (Thomas et al, 2005; Glazer et al, 2009). Qualitative and quantitative differences in techniques for determining EGFR positivity and cut-off levels may be significant factors contributing to the disagreement between studies. Nonetheless, the prognostic significance of EGFR in HNSCC in a great number of studies has compelled the development of therapeutic strategies to block EGFR signal transduction system and, theoretically, downregulate tumour growth. The use of antibodies against EGFR or inhibitors of tyrosine kinase in combination with chemotherapy or radiotherapy are underway in various cancer systems including HNSCC (Glazer et al, 2009; Chang \& Califano, 2008; Uribe \& Gonzalez; 2011).

Cyclin D1 (CCND1) is a proto-oncogene located on chromosome 11q13 involved in the regulation of cell cycle transitions. Overexpression of CCND1 has been shown to shorten the G1 phase of the cell cycle (Motokura \& Arnold, 1993). Abnormalities in cyclin D1 may result from genomic inversion, transloction or gene amplification (Leemans et al, 2011). However, overexpression may occur in the absence of gene amplification through a not wellcharacterized mechanism, which may precede gene amplification. Early dysregulation of CCND1 expression may occur during head and neck tumourigenesis (Izzo et al, 1998). Amplification and/or over-expression of CCND1 have been demonstrated in $17-79 \%$ of 
tumour specimens from HNSCC patients by IHC, FISH or RT-PCR. CCND1 shows a higher incidence in hypopharyngeal and laryngeal carcinomas between $41 \%$ and $64 \%$ and a rare incidence $(8 \%)$ in tonsillar carcinomas. Gene amplification is the most commonly reported alteration of CCND1. Its amplification and/or overexpression have been shown to correlate significantly with tumour extension, regional lymph node metastases and advanced clinical stage of HNSCC (Thomas et al, 2005; Quon et al, 2001). In addition, many studies show convincing data of CCND1 aberration as a prognostic marker for disease-free survival and overall survival in patients with this disease (Table 3). In particular, its overexpression was associated with an adverse disease free survival, independent of T and N (Quon et al, 2001). In contrast, other data found no significant associations between levels of CCND1 and survival of patients with HNSCC (Vielba et al, 2003). As most of the studies on CCND1 utilize IHC in paraffin-embedded tissue from patients with HNSCC to examine the expression of CCND1, reasons for the differences between these studies are not clearly evident. However, differences in parameters for grading immunohistochemical staining may account for some of these discrepancies. In addition, the retrospective selection of patients for analysis may influence the outcome of these studies. Several studies documented the independent value of cyclin D1 overexpression, particularly when combined with the loss p16 expression. In fact, significant correlation with poor clinical outcome measures of recurrence, metastasis and survival was seen when both of these genetic aberrations occur together than either alone (Thomas et al, 2005).

p16 protein, which is encoded by the CDKN2A tumour suppressor gene on chromosome 9p21, inactivates the function of cdk4-cdk6-cyclin D complexes (Leemans et al, 2011). Loss of heterozygosity of the short arm of chromosome 9 (9p21-22) has been reported with high frequency in dysplasia, carcinoma in situ and HNSCC, suggesting that this genetic alteration may be involved in the early developmental stages of this disease (Thomas et al, 2005). Loss of p16 expression, mostly homozygous deletions and methylations is present in 52-82\% of tumours from HNSCC patients using various detection techniques such as IHC and RT-PCR (Thomas et al, 2005). Using fluorescence in situ hybridization (FISH), p16 deletion was significantly associated with development of distant metastases (Table 3) (Namazie et al, 2002). In addition, using PCR-based techniques, a prospective study of locally advanced laryngeal SCC identified p16 mutation as an independent predictive factor for disease relapse and death (Bazan et al, 2002). In addition, downregulation of p16 was associated with a more locally advanced tumour (Thomas et al, 2005). HPV infection has an important role in understanding p16 role as a prognostic marker in HNSCC. It is well established that in HNSCC detected with HPV oncoproteins, p16 overexpression or TP53 wild type have a better prognosis (Leemans et al, 2011; Smith et al; 2010). In particular, HPV infection has been demonstrated to play a role in the molecular pathways through its viral oncoproteins, E6 and E7 (Chung \& Gillison, 2009). They increase degradation of p53 and interfere with pRB function leading to upregulation of p16 by loss of negative feedback control. It was shown that recurrence free-survival were highest in the HNSCC patients positive for HPV infection, having p53 wild type and overexpressing p16 (Leemans et al, 2011).

Cyclooxygenase (COX) is an enzyme that is responsible for the formation of prostanoids (prostaglandins, prostacyclins, and thromboxanes) which are involved in the inflammatory response. Two isoforms of Cox, Cox-1 and Cox-2, have been described. Although Cox-1 is 
constitutively expressed in various tissues, Cox-2 expression is undetectable in most tissues and may play an important role in carcinogenesis and in the pathophysiologic progression of HNSCC (Thomas et al, 2005; Lin et al, 2002). Overexpression of Cox-2 in premalignant lesions such as oral Leukoplakia and HNSCC by the techniques of quantitative RT-PCR, IHC or immunoblotting has detected (Thomas et al, 2005). Cox-2 expression can be induced by various stimuli including a variety of cytokines, hormones and tumour promoters such as benzopyrene, a carcinogenic agent involved in head and neck tumorigenesis. Cox-2 enzyme contributes to carcinogenesis by catalysing the synthesis of mutagens decreasing programmed cell death or apoptosis, increasing inflammation and immunosuppression, increasing new blood vessel formation or angiogenesis and increasing potential for invasion and metastasis (Eling et al, 1990; Tsujii \& DuBois, 1995; Gallo et al, 2001; Thomas et al, 2005). Cytoplasmic expression of Cox-2 has been demonstrated in $70-88 \%$ of specimens from HNSCC patients with HNSCC using IHC and in $87 \%$ of tumour specimens using RT-PCR. In addition, expression of Cox-2 is significantly higher in tumour specimens with confirmed cervical lymph node metastasis and in advanced and poorly differentiated tumours of HNSCC (Table 3) (Thomas et al, 2005). Expression of Cox-2 was also found to be a significant prognostic marker in patients with premalignant lesions (Sudbo et al, 2003), and is an independent predictor of disease-free survival (Itoh et al, 2003), but not overall survival in patients with OSCC. Interestingly, one study suggested that patients with Cox-2-negative tumours, measured using IHC and Western blot analysis, had a worse clinical outcome as compared to patients bearing a Cox-2-positive laryngeal SCC (Ranelletti et al, 2001). Furthermore, COX-2 expression was noted in all laryngeal cancer specimens using IHC, and again, a lack of correlation between Cox-2 expression and clinicopathologic variables such as primary tumour size, stage, survival, recurrence or metastases was reported for these patients (Thomas et al, 2005). Despite these results, numerous studies in various cancer systems suggest that Cox-2 activity is important in the progression of epithelial cancers.

Vascular endothelial growth factor-A (VEGF-A) is one of the key angiogenic factors promoting neovascularization in cancer, including HNSCC (Lim, 2005). It induces proliferation, migration and survival of endothelial cells during tumour growth by binding to specific tyrosine receptor kinases. Six members of the VEGF family have been identified: VEGF-A/ vascularpermeability factor (four isoforms), VEGF-B/VEGF-related factor, VEGFC/VEGF-related protein, VEGF-D/c-fos-induced growth factor, VEGF-E and placenta growth factor, and abnormal regulation of angiogenic factors have been implicated in the pathogenesis of cancer. In particular, VEGF-A has been described as an important prognostic factor in many types of human cancer (Thomas et al, 2005). Several retrospective studies in HNSCC have demonstrated that VEGF-A (Teknos et al, 2002) and VEGF-C (Tanigaki et al, 2004) expression is associated with clinicopathological factors and/or poor patient's outcome, suggesting that they could serve as a prognostic marker also in HNSCC (Table 3). Many studies have shown that VEGF-A, as well as VEGF-C, are upregulated in head and neck cancers, thus stimulating proliferation of vascular and lymphatic endothelial cells, and increasing vessel permeability (Thomas et al, 2005). The enhanced angiogenic activity could sustain growth of the primary tumour, potentiate dissemination and also support the establishment of micrometastases (Onesto et al, 2006). This is consistent with the strong association observed in different studies between VEGF-A expression and distant recurrence. It was also demonstrated that VEGF-A protein levels are closely associated to overall survival (Onesto et al, 2006). Subsequently, multivariate analysis showed that VEGF- 
A expression is an independent prognostic factor for overall survival. However, the status of VEGF-A remains unclear since other HNSCC retrospective studies have shown no correlation between VEGF-A expression and prognosis (Onesto et al, 2006; Thomas et al, 2005). These conflicting results may be due partly to the method of detection of VEGF-A expression (i.e.IHC), used in most of the previous reports, and which is a semiquantitative method. A contributing factor for these discrepant studies may be related to the lack of a direct technique to measure angiogenic activity in tissue specimens. By using a semiquantitative method (i.e. IHC) as well as a quantitative method (i.e. ELISA), it is shown that VEGF-A expression is significantly associated with the tumour differentiation stage, poorly differentiated tumours expressing higher VEGF-A levels than highly differentiated tumours in head and neck carcinomas (Onesto et al, 2006; Thomas et al, 2005). In conclusion, markers related to tumour neovascularization can also predict the outcome in head and neck cancer patients.

Transforming growth factor alpha (TGF-a) is upregulated in some human cancers, including HNSCC. It is produced in macrophages, brain cells, and keratinocytes, and induces epithelial development. It competes with EGF for EGFR binding, which also results in receptor activation and cellular proliferation. By using IHC analysis, it was demonstrated that TGF alfa is elevated in HNSCC and in the adjacent histologically normal mucosa compared to normal control mucosa. The prognostic significance of TGF alfa has not been as widely studied as that of EGFR, but there is suggestive evidence that its overexpression may predict an increased risk of recurrence and adverse survival in HNSCC patients (Table 3) (Quon et al, 2001; Leemans et al, 2011).

MMPs. The capacity of head and neck cancer to invade adjacent tissues and develop locoregional metastasis often presents serious problems in clinical management. Cancer cell invasion, metastasis and angiogenesis is a complex, multistep process, involving the cooperation of multiple proteolytic enzymes that are secreted by tumour and/or host cells and whose substrates include extracellular matrix (ECM) components. The matrix metalloproteinases (MMPs) are a family of zinc- and calcium-dependent endopeptidases that can collectively degrade virtually all protein components of the ECM. Degradation of collagen matrix is important for HNSCC to invade surrounding tissues and metastasize to regional and distant organs (Thomas et al, 2005; Lim, 2005) MMP-2 and MMP-9, believed to play a major role in tumour invasion and metastasis in HNSCC, degrade type IV collagen, the main component of basement membrane (Stetler-Stevenson et al, 1993). MMPs can be inactivated by naturally occurring tissue inhibitors of MMPs (TIMPs). Expression of TIMPs has also been associated with poor prognosis in HNSCC patients (Thomas et al, 2005). Various MMPs are over-expressed in HNSCC including MMP-2, MMP-8, MMP-9 and MMP-13 (Thomas et al, 2005; Ha et al, 2009). These have been detected mainly with the immunohistochemical analysis of paraffin-embedded primary tumours. MMP-9 is overexpressed in $60-92 \%$ of HNSCC and was positively correlated to the over-expression of proto-oncogene eIF4E (Nathan et al, 2002). Correlation of expression of MMP-9 with traditional clinicopathogic variables or with measures of clinical outcome in patients with HNSCC remains controversial (Table 3). Over-expression of MMP-9 has been significantly correlated with histologic grade, advanced tumour stage and lymph node metastases of HNSCC at diagnosis. Alternatively, the correlation between the expression of MMP-9 and traditional clinical prognostic factors such as tumour and lymph node stages has not been 
demonstrated in HNSCC patients (Thomas et al, 2005). Differences in the clinical stages of patients at presentations and differences in treatment modalities have been proposed as possible factors contributing to the discrepancies between these studies. The MMP-2 expression in HNSCC at the invasive front in advanced HNSCC was significantly correlated with overall survival, early recurrence in lymph node negative patients and lymph node metastasis (Table 3). In addition, studies from serum samples of HNSCC patients showed that high serum levels of soluble E-cadherine, MMP-9, active MMP-13, and presence of antibody anti-p53 were found to be significantly associated with poor survival and the presence of lymph node metastasis (Thomas et al, 2005). This demonstrates that the combined determination and evaluation of tumour markers may improve the diagnosis of lymph node metastasis in HNSCC. Finally, a recent study from a genome-wide transcriptional analysis of 25 HNSCC cell lines, having a different intrinsic cisplatin sensitivity, showed the possible use of MMP-7 and MMP-13, as novel predictive biomarkers for cisplatin resistance (Ansell et al, 2009).

FHIT, which is located at chromosome $3 \mathrm{p} 14.2$, is a tumour suppressor gene that is frequently deleted in human cancers, including HNSCC. Loss of Fhit protein expression has also been reported in some precancerous lesions of the oral cavity and esophagus (Tai et al, 2004). It has been found to be associated with exposure to environmental carcinogens, such as smoking and alcohol consumption. The loss or alterations of normal FHIT function in the context of cell growth or tumour suppression is still not known. The role of Fhit as a prognostic marker in patients with HNSCC has not yet been clearly ascertained (Table 3). Reduction or loss of Fhit expression can be found in 53-68\% of tumour samples from patients with HNSCC (Thomas et al, 2005). Data obtained by using IHC, Western blot and RT-PCR methods, show that a low FHIT expression correlated with high expression of Ki67, suggest that FHIT-altered tumour cells may have high proliferation potential (Mineta et al, 2003). However, only a few studies have found a significant correlation between Fhit expression and prognosis of patients with HNSCC. Patients whose tumours showed low or no expression of Fhit had significantly shorter disease-free survival (Lee et al, 2001; Tai et al, 2004). Interestingly, it has been shown that no reduction in Fhit expression by IHC predicted a significantly poorer outcome in patients with advanced oropharyngeal cancer (OteroGarcia et al, 2004). In this study, tumours from all patients that subsequently developed distant metastases showed no reduction of expression of Fhit. The authors did not provide a rationale for the discrepancy between their and other studies. In other studies, authors showed that loss of Fhit expression by IHC predicted significantly poorer overall survival and an increased rate of distant metastases in patients with HNSCC (Tai et al, 2004). The results of these studies suggest that Fhit expression, as a potential new marker in HNSCC, is still in question. Further studies to elucidate the potential role of this gene in HNSCC carcinogenesis are needed.

Several other molecular factors may provide potential prognostic information for HNSCC patients. PTEN (Table 3), Ki67 and Bcl-2 are three of them. Ki67 is a marker reflecting cellular proliferation. Bcl-2 plays an important role in regulating apoptosis. The data on the prognostic role for Bcl-2 in HNSCC remain contradictory. Existing data show an association of Bcl-2 overexpression with recurrence and poor survival. On the other hand, there are also studies in which no correlations with clinical outcomes are reported (Ha et al, 2009; Quon et al, 2001). 


\section{Molecular study of HNSCC}

HNSCC is a heterogeneous disease with complex molecular abnormalities. By using high throughput approaches generating gene expression and, more recently, microRNAs expression profiling, researchers may obtain a molecular classification and characterization of HNSCC, also in association with clinical parameters.

\subsection{Gene expression}

Gene expression signatures constitute an additional biological approach used to: identify screening and diagnostic molecular markers, improve tumour staging (cervical lymph node and distant metastasis prediction), differentiate lung metastasis of HNSCC from primary lung squamous cell carcinomas, predict tumour response to therapy, and provide outcome predictors (Lallemant et al, 2010). Two technologies are currently used: DNA microarrays, which extensively measures the expression of thousands of genes, and qRT-PCR, which provides a more accurate quantification of the expression of more limited number of transcripts. From a clinical point of view, gene expression profiling should provide more accurate information about the cancer consequently leading to a more personalized and improved treatment strategy (Choi \& Chen, 2005). To date, more than 60 gene expression profiling studies from human clinical samples of HNSCC have been published, with variable objectives, methods and results. The most significant source of heterogeneity among DNA microarray profiling studies comes from the various methods of data generation and analysis. All microarray data analyses consist of two basic steps: 1) establishing a normalized hybridization signal for each transcript and 2) the subsequent statistical determination of the signal variations. Perhaps, the largest drawback of microarray-based examinations of HNSCC is the lack of a well-defined standard for their use, interpretation and validation. Variability in tissue procurement, tumour cell isolation, RNA extraction, choice of array platform can also explain the differences among several HNSCC gene expression studied. For instance, some authors included samples from different HNSCC locations, others focused on a specific site; some analyzed microdissected tumour epitheliums, others including the surrounding stroma (Choi \& Chen, 2005). Furthermore, most studies relied on a very limited number of samples. Consequently, it is important to set a threshold percentage value of tumour cells content and the contribution of stromal cell contamination to genetic expression profiles. Another consideration in microarray experimental planning is choosing appropriate controls. It is possible to use matched or unmatched normal tissue samples as a control, in which matched tissue is taken from the same patient from whom the tumour sample was obtained, while unmatched sample is obtained from subjects without cancer. However, from the pooled gene expression data, it was possible to identify a group of genes reported by multiple studies to be significantly up-regulated and down-regulated in HNSCC (Choi \& Chen, 2005; Lallemant et al, 2010). These genes were used to encode cytoskeletal and extracellular matrix proteins, inflammatory mediators, proteins involved in epidermal differentiation and cell adhesion molecules (Choi \& Chen, 2005). Data suggested a global downregulation of genes that encode ribosomal proteins and enzymes in the cholesterol biosynthesis pathway, and an upregulation of genes that encode matrix metalloproteinases and genes involved in the inflammatory response (Choi \& Chen, 2005). 


\subsubsection{Identification of HNSCC in body fluids: Blood and saliva}

During carcinogenesis, some cancer cells may migrate into the blood stream or be eliminated into natural cavities like the bladder, mouth and intestines. Recovering transcriptional biomarkers representing genetic cancer alterations in the serum, plasma, urine, semen or saliva of patients, have already proven to be feasible and potentially useful, even if to date there are a few and preliminary results (Sidransky et al, 1997; Lallelmant et al, 2010). In a study, researchers compared a gene expression profile in the blood serum of HNSCC patients and control cases, aiming to identify a signature of 5 overexpressed genes and demonstrate the utility of serum in the HNSCC diagnosis. It is important to note that diagnostic biomarker detection in saliva of HNSCC patients is a promising field of research. To date, most studies have focused on DNA alterations (mutations or methylation) and only recently on mRNA detection. Among the genes correlated with the HNSCC diagnosis identified from the saliva, there are IL1beta, OAZ1, SAT, IL8, SAT and H3F3A (Li et al, 2006; Lallelmant et al, 2010).

\subsubsection{Gene expression profile and local metastasis prediction}

Metastatic spread is an extremely bad prognostic factor. It is responsible for the cause of death in $90 \%$ of all cancer patients (Mehlen \& Puisieux, 2006). When cervical lymph node metastases are identified, more aggressive treatments are proposed either by surgery or radiotherapy. In presence of distant metastases, the disease is considered incurable and palliative treatments are indicated. Differences between metastatic and non-metastatic tumours may be detected. Data from fourteen studies demonstrated that specific differences in gene expression exist between N+ and N0 HNSCC (Lallemant et al, 2010).This difference can be used to predict the $\mathrm{N}$ status on initial diagnostic biopsy. On the contrary, a few studies have tried to find gene expression signatures that could predict the development of distant metastasis in HNSCC, but to date, poor results have been obtained (Choi \& Chen, 2005). Insufficient samples number may in part explain the failure of these studies. In this aspect HNSCC differs from other tumour types, such as breast or prostate cancer, where a metastasis signature was identified. Cervical lymph nodes seem to work as a filter for metastatic cells and could be a prerequisite in hematologic spread. The acquisition by the primary tumour of a metastatic genetic profile is not inevitably associated with the occurrence of a distant metastasis because this cervical immunological fence can prevent or delay their appearance (Braakhuis et al, 2006).

One of the main difficulties during the diagnosis of HNSCC is detecting microscopic tumour clusters, known to be easily overlooked by conventional histopathological methods in lymph nodes and/or surgical margins (Lallemant et al, 2010). Micrometastases are responsible for cancer recurrence in the neck of patients classified as N0 and, who consequently did not receive a prophylactic treatment either by neck dissection or radiotherapy. Additional biomarkers may be of help to improve stratifying patients selected for sentinel node biopsy. As suggested by preliminary results, gene expression signatures may greatly facilitate the identification of micrometastases in N0 patients. In the same way, the development of high frequency recurrence may be due to the presence of microscopic cancer cells cluster in the resection margins disregarded by conventional microscopy (Lallemant et al, 2010). Among the molecular markers with proven predictive value for lymphatic disease are E-cadherin, podoplanin, p16, bmi-1 and LOX (Huber et al, 2011; 
Lallemant et al, 2010). Until now, the published predictive factors for metastatic disease in early HNSCC are histomorphological parameters, like mode of invasion, depth of tumour infiltrations, grade of differentiation, lymphatic invasion and intratumoral lymphatic density (Huber et al, 2011). The combination of these identified molecular markers and the histopatological features could allow individual risk stratification with possible impact on treatment strategy.

\subsubsection{Gene expression to distinguish HNSCC lung metastasis}

In many cases, the most common site of a HNSCC distant metastasis is the lung tissue (Ferlito et al, 2001). Knowledge of whether this tumour is a lung primary cancer or an HNSCC metastasis is crucial in the patient's decision making process in choosing treatment. Unfortunately, in the presence of a single pulmonary nodule of squamous cell origin, the distinction between the primary lung tumour and HNSCC metastasis is impossible to discern (Lallemant et al, 2010). To date, only two studies have tried to address this issue by using gene expression approach. A signature of 10 genes correctly predicted and identified the origin of the tumour, thus suggesting the likelihood in identifying the origin of histologically similar malignant lesions based on expression profiling (Vachani et al, 2007).

\subsubsection{Correlation between gene expression profiling and clinical outcomes}

Gene expression profiling in relation to outcome prediction has been investigated to help clinicians to better stratify patients according to tumour aggressiveness, define prognosis, and subsequently modulate treatment intensity. The first study that reported the possible use of gene expression profiling for outcome prediction identified a 375 gene signature that divides the 17 patients of their cohort into two groups with slightly different survivals (Belbin et al, 2002). Data from different studies show a set of genes which identify HNSCC patients with high and low risk of recurrence and survival (Lallemant et al, 2010). For instance, it seems that high level of osteonectin may be a powerful, independent predictor for short-disease free survival interval and poor overall survival. A few studies also combined DNA microarray and CGH data to correlate the gene expression changes with chromosomal dosage and structure alterations (Lallemant et al, 2010). To date, the ability of gene expression profiling to provide effective outcome predictor remains questionable and extremely challenging.

In HNSCC, choosing the most efficient treatment for each patient is based on a TNM evaluation. However, a certain percentage of patients do not respond to treatment. Thus, the differences in gene expression profiles between responders and non responders may be identified. To date, only few studies have addressed this specific issue in relation to HNSCC (Lallemant et al, 2010). Among the identified potentially predictive genes for therapy response there are MDM2, erb2, H-ras, VCAM-1 (Ganly et al, 2007). However, although these studies provide support for the use of gene expression in predicting treatment response, their results are disappointing. Another confounding factor could be the combination of treatments used, consisting of two distinct biological mechanisms of action. Ongoing studies focusing on the development of a predictive response signature for radiotherapy alone or chemotherapy alone are more likely to be successful (Lallemant et al, 2010). 


\section{2 microRNAs expression profiling in HNSCC}

A class of small non-coding RNAs termed microRNAs (miRNAs) has recently been indicated as biomarker of some types of cancers (Nana-Sinkam \& Croce, 2010). miRNAs are endogenous, small, non-coding RNAs of 17-25 nucleotides that are thought to regulate approximately $30 \%$ of human genes. miRNAs modulate gene expression at posttranscriptional level, primarily through their partial complementarity with the coding region or 3' untranslated region (UTR) of target mRNAs. This then leads to translational repression and/or degradation, therefore, the regulation of gene expression (Babu et al, 2011). In rare cases, they may also promote translation (Lin et al, 2011).They are involved in essential biological activities such as cellular differentiation, proliferation, development, apoptosis and cell cycle regulation (Shiiba et al, 2010). The roles of miRNAs in cancer have been extensively investigated in the past few years. The relevance of miRNAs in cancer was suggested by the observed changes in expression patterns and recurrent amplification as well as deletion of miRNA genes in cancer (Shiiba et al, 2010; Chen et al, 2010). It has been shown that there are two types of cancer-related miRNAs: oncogenic or tumour suppressor miRNAs (Table 4) (Babu et al, 2011). miRNAs expression profiling has been performed by microarray analysis or qRT-PCR methods. Some microRNAs show consistently altered expressions by different studies. For example, the upregulated expression of miR-21, $-31,-18$ and -221 has been reported in at least two different studies. Similarly, the expression of the miR-133a, -133b, -125a, -138, -139, -200c, -26b, -302b, -302c, -342, -371, and -373 is consistently reported to be down regulated in HNSCC (Shiiba et al, 2010). Except certain miRNAs, all published miRNAs profiling show little agreement. This may be due to various types of samples applied, to different qualities of material (FFPE or fresh tissue), different sampling locations/cell lines, methods for performing the assay and scope of the array. The sampling technique of the tumour tissue also influenced the proportion of tumor cells to non-tumor cells that may interfere with the sensitivity of real time PCR and microarray analysis.

\subsubsection{Functional analysis of miRNAs in HNSCC}

Potential tumour suppressor miRs: Several miRNAs are found to act as tumour suppressors in cancer and in HNSCC (Table 4). Reduced expression of almost all members of let-7 family has been observed in HNSCC by several studies (Babu et al, 2011). For example, it is shown that exogenous expression of let-7a promotes laryngeal cancer cells dysfunction by modulating proliferation, inhibiting metastasis and inducing apoptosis (Long et al, 2009). In addition, it was shown that let-7a affects RAS and c-Myc expression at protein level, thus leading to the modulation of apoptotic genes and oncogenes expression. Furthermore, reducing it into let-7d expression is associated with poor prognosis (Childs et al, 2009). Down regulation of miR-125a/b is also observed in HNSCC by independent studies. Functional data that involve introducing miR-125b into HNSCC cell lines result in a reduced cell proliferation. A possible molecular mechanism contributing to this effect might be ERBB2 targeting by miR-125a/b which has experimentally been demonstrated. In fact, a high level of ERBB2 expression was observed in HNSCC suggesting disruption of miRNA suppression of this gene (Babu et al, 2011). Down regulation of miR-133a/b was also reported. Knocking-in these miRs in HNSCC cells resulted in reduced cell proliferation or increased apoptosis (Wong et al, 2008 (a)). An increased levels of PKM2, the validated cellular target of miR-133a/b, has also been associated with cancer progression (Wong et al, 
2008 (a)). Members of miR-200 family, such as miR-200a and miR-200b, are also down regulated in HNSCC. They target ZEB1/2, which act as transcriptional repressors of Ecadherin. In this way, the down modulation with the miR-200 family, concomitantly to the overexpression of miR-155, may promote epithelial mesenchymal transition (EMT) (Babu et al, 2011; Chen et al, 2010). In addition, the role of miR-138 in metastasis has also been demonstrated; miR-138 modulates migration and invasion through targeting RhoC and ROCK2. The inhibition of miR-138 enhanced cell migration as well as invasion (Liu et al, 2009). The expression of other miRs, such as miR-34c and miR-204, also correlates with invasion. Enhancing miR-204 expression directly leads to the reduction of proliferation, invasion and migration in HNSCC cell lines (Lee et al, 2010). Also microRNAs can be silenced by hypermethylation for the tumor suppressor genes. miR-137 and 193a are an example; they are downregulated in HNSCC (Kozaki et al, 2008). In addition, miR-137 promoter hypermethylation is significantly associated with poorer average survival in a study of 67 HNSCC patients (Langevin et al, 2010).

Potentional oncogenic miRs: Several miRNAs are found to act as oncogenic miRs in cancer and in HNSCC (Table 4). Overexpression of miR-106b-25 and 17-92 clusters was observed in cancer, including HNSCC, by independent studies (Babu et al, 2011; Shiiba et al, 2010). These clusters, targeting p21 mRNA, are linked with cell cycle dysfunction. In fact, knockdown of both clusters in HNSCC cells results in a reduced proliferation rate. miRNAmediated deregulation of p21 is likely to play an important role in tobacco associated HNSCC carcinogenesis because it can negatively regulate p53-mediated DNA damage induced by carcinogens in tobacco smoke (Ivanovska et al, 2008). Another overexpressed putative oncogenic miR identified in HNSCC is miR-221, which is able to suppress the expression of cell cycle regulators p27 and p57 (Babu et al, 2011). Reduced expression of p27 has been well reported in HNSCC. It has even been suggested that it may act as a biomarker for cancer progression (Queiroz et al, 2010). In addition, a role of the miR-106b-25 and 17-92 clusters in controlling TGF-beta signaling pathway, which is deregulated in HNSCC, is emerging (Leemans et al, 2011). Another common deregulation in miRs expression in HNSCC is the upregulation of miR-21. Transfection of this miR into HNSCC cell lines results in significant increased growth rate whereas inhibitor-driven knock-down of miR-21 reduces cell proliferation. Furthermore, the inhibition of miR-21 was demonstrated to enhance cytocrome-c release, thereby promoting apoptosis (Babu et al, 2011). Finally, miR155 shows an increased level of expression in several cancers including HNSCC and its possible role in the carcinogenesis has been investigated (Babu et al, 2011).

\subsection{2 miRNAs as prognostic and diagnostic biomarkers associated with HNSCC: Correlation with clinical outcomes}

Several investigators have empathized the role of miRs as biomarkers for HNSCC (Table 5). In a recent study focusing on identifying miRNAs expression signatures in association with progressive leukoplakia using sequentially progressive samples, researches built a multimiR prognosis predictor (Cervigne et al, 2009; Babu et al, 2011). The predictors are composed of eight miRs. According to the proposed model of miR changes during the progression from leukoplakia to OSCC, the over-expression of a subset of miRs (miR-146b, miR-181b, miR-21, miR-345, mR-518b, miR-520g, miR-649 and miR-184) may be considered an early detectable event in oral tumour progression. This is because they were commonly 


\begin{tabular}{|c|c|}
\hline Oncogenic miRs & References \\
\hline miR-106b-25 cluster & $\begin{array}{l}\text { - Ivanovoska et al, 2008; } \\
\text { - Petrocca et al, } 2008 \text {. }\end{array}$ \\
\hline miR-17-92 cluster & - Petrocca et al, 2008 \\
\hline miR-221 & - Avissar et al, 2009 (a) \\
\hline miR-21 & $\begin{array}{l}\text { - Cervigne et al, 2009; } \\
\text { - Kimura et al, } 2010 .\end{array}$ \\
\hline miR-155 & $\begin{array}{l}\text { - Chang et al, 2008; } \\
\text { - Hui et al, 2010; } \\
\text { - Ramdas et al, 2009. }\end{array}$ \\
\hline miR-31 & - Liu et al, 2010 \\
\hline miR-184 & $\begin{array}{l}\text { - Wong et al, } 2008 \text { (b); } \\
\text { - Wong et al, } 2009 .\end{array}$ \\
\hline $\begin{array}{l}\text { Tumor suppressor } \\
\text { miRs }\end{array}$ & - References \\
\hline Let-7 family & $\begin{array}{l}\text { - Chang et al, 2008; } \\
\text { - Hui et al, 2010; } \\
\text { - Ramdas et al, } 2009 .\end{array}$ \\
\hline miR-125a/b & $\begin{array}{l}\text { - Henson et al, 2009; } \\
\text { - Park et al, } 2009 .\end{array}$ \\
\hline miR-133a/b & - Nohata et al, 2011 \\
\hline miR-200 family & - Park et al, 2009; \\
\hline miR-1 & - Nohata et al, 2011 \\
\hline
\end{tabular}

Table 4. Altered microRNAs in HNSCC

deregulated in progressive and malignant lesions and were unchanged or under-expressed in non-progressive lesions. In particular, miR-345, miR-21 and miR-181b are strongly associated with increased lesion severity during the transition from histologically premalignant to malignant lesions. According to this model, the final stages of carcinogenesis may also involve changes in miR-196a and miR-206, which appear under-expressed in premalignant lesions and over-expressed in carcinomas. Interestingly, these miRs are predicted to target cancer-associated genes, e.g. TNFRSF10B, ACAT1, NFIB, CCL1, MSH2, ACYP1 and PCBP2 (miR-21); GRM1, MAP3K10, CCDC42, SNHG5 (miR-181b); TSPO, RFXDC1, ZNF133, MORN3 (miR-345) (Cervigne et al, 2009). However, the usefulness of miRs as prognostic factors has only begun to be explored. Data from the study of miR-205 and Let-7d expression showed their association with locoregional occurrence and shorter survival (Childs et al, 2009). In addition, high expression of miR-205 can be used to detect positive lymph nodes, suggesting that this miR can be considered as a marker for metastatic HNSCC (Fletcher et al, 2008). Another similar study identified lower expression levels of miR-451 in HNSCC tumours as a strong predictor for recurrence (Hui et al, 2010). In a study that looked into identifying diagnostic miRs in the saliva, researchers reported significantly low levels of miR-125a and 200a in the saliva of OSCC patients compared to control subjects (Park et al, 2009). Another recent study reported high levels of miR-184 and miR-31 in plasma of OSCC (Wong et al, 2008 (b), 2009). The study also showed that miR-184 has antiapoptotic functions in HNSCC cell lines. In fact, the inhibition of its expression can reduce cell proliferation rates. Finally, an association with higher expression of miR-211 and 
most advanced nodal metastases, vascular invasion and poor prognosis was demonstrated in HNSCC (Chang et al, 2008).

\begin{tabular}{|c|c|c|}
\hline $\begin{array}{l}\text { Putative miR } \\
\text { marker }\end{array}$ & Properties as marker & References \\
\hline mir-205 & $\begin{array}{ll}> & \text { Prognostic value: } \\
> & \text { low expression is associated with loco-regional } \\
& \text { recurrence. } \\
> & \text { low expression of both miR-205 and let-7d is } \\
\text { associated with poor survival } \\
>\quad \text { role of miR-205 down-regulation in epithelial- } \\
\text { mesenchymal transition of head and neck } \\
\text { spindle cell carcinoma } \\
>\text { miR-205 expression as a marker for detection } \\
\text { of metastatic HNSCC }\end{array}$ & $\begin{array}{l}\text { - Childs et al, 2009; } \\
\text { - Fletcher et al, 2008; } \\
\text { - Kimura et al, 2010; } \\
\text { - Zidar et al, 2011. }\end{array}$ \\
\hline Let-7d & $\begin{array}{l}>\text { Prognostic value: } \\
\text { down-regulation of let-7d in combination with } \\
\text { miR-205 low expression is associated with } \\
\text { poor survival } \\
>\quad \text { let-7d down-regulation promotes epithelial- } \\
\text { mesenchymal transition (EMT) and have a role } \\
\text { in chemoresistance }\end{array}$ & $\begin{array}{l}\text { - Chang et al, 2011; } \\
\text { - Childs et al, } 2009 .\end{array}$ \\
\hline miR-211 & $\begin{array}{l}>\text { Prognostic value: } \\
>\text { high miR-211 expression is associated with a } \\
\text { worse survival rate }\end{array}$ & - Chang et al, 2008 \\
\hline miR-31 & $\begin{array}{l}\text { Diagnostic marker: } \\
\text { detection of high miR-31 expression in plasma } \\
\text { from oral cancer patients } \\
\text { miR-31 expression in plasma is remarkably } \\
\text { reduced after tumor resection }\end{array}$ & - Liu et al, 2010. \\
\hline miR-125a, 200a & $\begin{array}{l}\text { Diagnostic marker: } \\
\text { detection of low miR-125a and miR-200a } \\
\text { expression levels in the saliva of oral cavity } \\
\text { cancers }\end{array}$ & - Park et al, 2009. \\
\hline miR-184 & $\begin{array}{l}\text { Diagnostic marker: } \\
\text { detection of high mir-184 expression in plasma } \\
\text { from oral cancer patients } \\
\text { miR-184 expression in plasma is remarkably } \\
\text { reduced after tumor resection }\end{array}$ & $\begin{array}{l}\text { - Wang et al, 2009; } \\
\text { - Wong et al, } 2008 \text { (b). }\end{array}$ \\
\hline $\operatorname{miR}-137$ & $\begin{array}{l}>\text { Prognostic marker: } \\
\text { miR-137 promoter methylation is associated } \\
\text { with poor overall survival } \\
\text { miR-137 aberrant methylation is more evident } \\
\text { in female gender }\end{array}$ & - Langevin et al, 2010. \\
\hline miR-21 & $\begin{array}{l}>\text { Prognostic value: } \\
\text { elevated miR-21 level was associated with } \\
\text { worse survival outcome; } \\
\text { high expression of miR-21, in combination } \\
\text { with miR-181b and miR-345 is associated with } \\
\text { increased severity during progression }\end{array}$ & $\begin{array}{l}\text { - Avissar et al, } 2009 \text { (a); } \\
\text { - Cervigne et al, 2009; } \\
\text { - Fu et al, 2011; } \\
\text { - Kimura et al, } 2010 .\end{array}$ \\
\hline
\end{tabular}




\begin{tabular}{|l|l|l|}
\hline $\begin{array}{l}\text { Putative miR } \\
\text { marker }\end{array}$ & Properties as marker & References \\
\hline miR-210 & $>\begin{array}{l}\text { Marker of hypoxia and prognostic/predictive } \\
\text { value: demonstrated functional role in tumor } \\
\text { survival under hypoxia }\end{array}$ & - Gee et al, 2010 \\
\hline miR-451 & $>$ Strong predictor for relapse & - Hui et al, 2010 \\
\hline miR-221, miR-375 & $>\begin{array}{l}\text { Diagnostic marker: } \\
\text { the expression ratio of miR-221 to miR-375 can } \\
\text { distinguish the normal from tumor tissue }\end{array}$ & - Avissar et al, 2009 (a) \\
\hline
\end{tabular}

Table 5. microRNAs as putative biomarker in HNSCC

\subsubsection{Aetiologic agents and correlation with miRNAs expression}

Despite the relative recent discovery of microRNAs and their association with cancer, their correlation with the aetiologic agents of HNSCC is still ongoing. Until now, very few studies have focused on this area. Data from multivariate analyses showed that expression of miR375 increases with alcohol consumption. Though expression of miR-375 is lower in tumours compared to normal tissues, fine-tuning of miRNA expression can occur at the level of the tumour microenvironment and can vary according to exposures and locations of the tumour (Avissar et al, 2009 (b)). In this case, alcohol consumption may contribute to the altered expression of miR-375 within HNSCC tumours. The regulation of miRNAs is complex and perturbations of the normal homeostatic mechanisms responsible for overall epigenetic stability could play a crucial role in potentially carcinogenic gene expression. Higher expression of miR-375 was also found in pharyngeal and laryngeal tumours compared with tumours of the oral cavity (Avissar et al, 2009 (b)). This observation is consistent with several findings indicating that miRNA profiles are tumour and cell-type specific which can even accurately differentiate tumour subtypes. Furthermore, the productivity for differential expression of miR-375 in tissues might reflect etiology. The significant association observed between drinking and miR-375 expression coupled with its tendency for higher expression in pharyngeal and laryngeal tumours may suggest that the deregulation of miRNA by exposures occurs preferentially in certain tissues (Avissar et al, 2009 (b)). Until now, there is no apparent evidence on the correlation of microRNAs expression and tobacco smoke in HNSCC. It is known that alcohol and tobacco use are predisposing factors for developing HNSCC, but HPV is also known to be associated with HNSCC, especially in the oral cavity and oropharynx cancer. HPV positive tumours have distinct clinical, molecular and prognostic features (Leemans et al, 2011). Until now, there is only one study on the microRNAs expression profiling analysis and HPV status information of HNSCC patients (Lajer et al, 2011). Researchers using a microarray approach have observed that HPV clearly has an influence on the miRNAs expression profile on a set of 49 oral cavity and oropharynx patients compared to 39 control subjects. In particular, miR-145, 125a, and 126 were reduced in HPV-positive HNSCC patients, while miR-363 expression was increased (Lajer et al, 2011).

\subsubsection{An overview on therapy in HNSCC: Curcumin as a potential therapeutic agent}

Standard treatment regimens for head and neck cancer depend on the stage of the disease. Early stage (stage I and II) tumours are treated primarily with surgery or radiotherapy, or 
with a combination of both modalities resulting in similar local control and survival rates. Radiation may also be used postoperatively when surgical margins are close or positive, or if a perineural or lymphovascular invasion by tumour is found. More advanced (stage III and IV) cancers often require a combination of therapies consisting of surgery, radiation and chemotherapy which can result in a very high morbidity (Wilken et al, 2011). Platinumbased agents form the backbone of the standard chemotherapeutic regimens for head and neck cancer. Cisplatin (cis diamminedichloroplatinum) is a widely used drug in the class of platinum-based chemotherapies. The efficacy of cisplatin in HNSCC is greatly increased when combined with other chemotherapeutic agents, such as taxanes (paclitaxel and docetaxel) and 5 fluorouracil (5-FU) (Adelstein et al, 2010). The potential adverse effects from the treatment for HNSCC are numerous (Wilken et al, 2011). Despite continuing research and advances in treatment, the clinical outcomes and overall survival rates for HNSCC have not improved significantly over the last several decades, with an overall 5year survival rate as low as $50 \%$. As a result, there has been continuing investigation into potential alternative and less toxic therapies for head and neck cancer, aiming to achieve a more favorable clinical outcome while reducing treatment morbidity. The class of molecularly targeted therapies against the epidermal growth factor receptor (EGFR) is one such example, as EGFR is overexpressed in a number of head and neck cancers (Chang \& Califano, 2008). Cetuximab is an anti-EGFR monoclonal antibody that was approved by the Food and Drug Administration in 2004 for the treatment of advanced colon cancer. In 2006, Cetuximab was approved for use in head and neck squamous cell carcinoma both in combination with radiotherapy for advanced HNSCC as well as single-agent therapy for platinum-refractory head and neck cancer. Several studies of cetuximab as an adjuvant agent with radiotherapy have demonstrated improved locoregional control and statistically significant increases in both progression-free and overall survival (Wilken et al, 2011). The addition of cetuximab to standard platinum-based chemotherapy in platinum-resistant recurrent or metastatic head and neck cancer has also been studied and demonstrated increased treatment efficacy and improved overall survival without a significant increase in toxicity (Wilken et al, 2011). Multiple molecular pathways such as NF-kB activation, EGFR and PI3K/AKT/mTOR signaling, STAT3 expression, the MAP kinase cascade and VEGF mediated angiogenesis have been shown to be deregulated in HNSCC and represent potential therapeutic targets (Choi \& Chen, 2005; Leemans et al, 2011). While some promising results from such targeted therapies have been obtained, the complexity of interaction between these signaling pathways may contribute to the limited clinical response seen with the use of single-agent biologic therapies. Curcumin (diferuloylmethane) is a polyphenol derived from the Curcuma longa plant, commonly known as turmeric. Curcumin has been used extensively in Ayurvedic medicine for centuries, as it is nontoxic and has a variety of therapeutic properties including anti-oxidant, analgesic, anti-inflammatory and antiseptic activity (Wilken et al, 2011). More recently curcumin has been found to possess anti-cancer activities, mostly via its effect on a variety of biological pathways involved in mutagenesis, oncogene expression, cell cycle regulation, apoptosis, tumorigenesis and metastasis (Wilken et al, 2011). Curcumin has shown an anti-proliferative effect in multiple cancers, and is an inhibitor of the transcription factor NF-kB and downstream gene products (including c-myc, Bcl-2, COX-2, NOS, Cyclin D1, TNF-alpha, interleukins and MMP-9). In addition, curcumin affects a variety of growth factor receptors and cell adhesion molecules 
involved in tumour growth, angiogenesis and metastasis (Wilken et al, 2011). As a natural product, curcumin is nontoxic. It has been studied in various in vitro and vivo models of head and neck squamous cell carcinoma with promising results. An overview of the current literature supports the spice's utility in the treatment of head and neck cancer and its effect as a chemopreventive agent (Wilken et al, 2011).

\section{Conclusions}

To date, the study of molecular prognostic factors has been an evolution motivated by the desire to define more homogenous groups of patients for treatment selection. Expression of these markers in diagnostic biopsy specimens may be an additional tool for selecting patients that may benefit from more aggressive treatment. Although these findings may help focus on selecting markers for further analysis for their value in the understanding and management of HNSCC, there are limitations to utilizing the list of molecules such as genes, microRNAs or proteins. Disagreement between studies may be due to the variety of tumour sites, sensitivity of the techniques used, quality of the specimens studied and the arbitrary cut-off values setted. More importantly, a lack of uniformed curative protocols throughout these studies may significantly affect their outcome, as the choice of a treatment method may have a great impact on long term survival of HNSCC patients. Although the pathobiology of many of the biomarkers in HNSCC provides sufficient rationale for clinical trials on single potential therapeutic agents, a multimarker strategy in addition to clinical parameters, is likely to add importance to the risk management of patients with or at risk of HNSCC. In this regard, microarray technology may provide a means for screening HNSCC samples for the presence or absence of a large number of genes or other molecules simultaneously. Many studies strongly suggest that miRNAs play a crucial role and may be a biomarker in HNSCC. There is a great deal of evidence demonstrating how altered expression of selected miRNAs may contribute to the deregulation of biological pathways involved in cancer such as cell cycle, apoptosis, epithelial-mesenchimal transition. Elucidation of the molecular mechanisms for miRNAs that are strong predictors of clinical outcomes can lead to a more complete picture of the role of miRNAs in HNSCC. Thus, detailed investigations of miRNAs, concerning intercommunication among miRNAs and between miRNAs and mRNAs, altered protein expression induced by miRNAs and site specific miRNAs expression profiling, are required accordingly before future clinical trials of therapeutic applications. For instance, antisense targeting of miRNAs for therapeutic purposes is emerging as a promising approach.

\section{References}

Adelstein, D. J., Moon, J., Hanna, E., Giri, P. G., Mills, G. M., Wolf, G. T., \& Urba, S. G. (2010). Docetaxel, Cisplatin, and Fluorouracil Induction Chemotherapy Followed by Accelerated Fractionation/Concomitant Boost Radiation and Concurrent Cisplatin in Patients with Advanced Squamous Cell Head and Neck Cancer: A Southwest Oncology Group Phase II Trial (S0216). Head Neck, Vol. 32, No. 2, (Feb 2010), pp. 221-228, ISSN 1097-0347

Akervall, J. A., Michalides, R. J., Mineta, H., Balm, A., Borg, A., Dictor, M. R., Jin, Y., Loftus, B., Mertens, F., \&Wennerberg, J. P. (1997). Amplification of Cyclin D1 in Squamous Cell Carcinoma of the Head and Neck and the Prognostic Value of Chromosomal 
Abnormalities and Cyclin D1 Overexpression. Cancer, Vol. 79, No. 2, (Jan 1997), pp. 380-389, ISSN 0008-543X

Almadori, G., Cadoni, G., Galli, J., Ferrandina, G., Scambia, G., Exarchakos, G., Paludetti, G., \& Ottaviani, F. (1999). Epidermal Growth Factor Receptor Expression in Primary Laryngeal Cancer: An Independent Prognostic Factor of Neck Node Relapse. Int J Cancer, Vol. 84, No. 2, (Apr 1999), pp. 188-191, ISSN 0020-7136

Ambrosch, P., Schlott, T., Hilmes, D., \&Ruschenburg, I. (2001). P16 Alterations and Retinoblastoma Protein Expression in Squamous Cell Carcinoma and Neighboring Dysplasia from the Upper Aerodigestive Tract. Virchows Arch, Vol. 438, No. 4, (Apr 2001), pp. 343-349, ISSN 0945-6317

Ansell, A., Jerhammar, F., Ceder, R., Grafstrom, R., Grenman, R., \&Roberg, K. (2009). Matrix Metalloproteinase-7 and -13 Expression Associate to Cisplatin Resistance in Head and Neck Cancer Cell Lines. Oral Oncol, Vol. 45, No. 10, (Oct 2009), pp. 866-871, ISSN 1368-8375

Avissar, M., Christensen, B. C., Kelsey, K. T., \&Marsit, C. J. (2009). MicroRNA Expression Ratio Is Predictive of Head and Neck Squamous Cell Carcinoma. Clin Cancer Res, Vol. 15, No. 8, (Apr 15 2009), pp. 2850-2855, ISSN 1078-0432

Avissar, M., McClean, M. D., Kelsey, K. T., \&Marsit, C. J. (2009). MicroRNA Expression in Head and Neck Cancer Associates with Alcohol Consumption and Survival. Carcinogenesis, Vol. 30, No. 12, (Dec 2009), pp. 2059-2063, ISSN 1460-2180

Babu, J. M., Prathibha, R., Jijith, V. S., Hariharan, R., \&Pillai, M. R. (2011). A Mir-Centric View of Head and Neck Cancers. Biochim Biophys Acta, Vol. 1816, No. 1, (Aug 2011), pp. 67-72, ISSN 0006-3002

Baez, A. (2008). Genetic and Environmental Factors in Head and Neck Cancer Genesis. J Environ Sci Health C Environ Carcinog Ecotoxicol Rev, Vol. 26, No. 2, (Apr-Jun 2008), pp. 174-200, ISSN 1532-4095

Balz, V., Scheckenbach, K., Gotte, K., Bockmuhl, U., Petersen, I., \& Bier, H. (2003). Is the P53 Inactivation Frequency in Squamous Cell Carcinomas of the Head and Neck Underestimated? Analysis of p53 Exons 2-11 and Human Papillomavirus 16/18 E6 Transcripts in 123 Unselected Tumor Specimens. Cancer Res, Vol. 63, No. 6, (Mar 2003), pp. 1188-1191, ISSN 0008-5472

Bazan, V., Zanna, I., Migliavacca, M., Sanz-Casla, M. T., Maestro, M. L., Corsale, S., Macaluso, M., Dardanoni, G., Restivo, S., Quintela, P. L., Bernaldez, R., Salerno, S., Morello, V., Tomasino, R. M., Gebbia, N., \& Russo, A. (2002). Prognostic Significance of P16ink4a Alterations and 9p21 Loss of Heterozygosity in Locally Advanced Laryngeal Squamous Cell Carcinoma. J Cell Physiol, Vol. 192, No. 3, (Sep 2002), pp. 286-293, ISSN 0021-9541

Beckhardt, R. N., Kiyokawa, N., Xi, L., Liu, T. J., Hung, M. C., el-Naggar, A. K., Zhang, H. Z., \& Clayman, G. L. (1995). Her-2/Neu Oncogene Characterization in Head and Neck Squamous Cell Carcinoma. Arch Otolaryngol Head Neck Surg, Vol. 121, No. 11, (Nov 1995), pp. 1265-1270, ISSN 0886-4470

Behm-Ansmant, I., Kashima, I., Rehwinkel, J., Sauliere, J., Wittkopp, N., \&Izaurralde, E. (2007). mRNA Quality Control: An Ancient Machinery Recognizes and Degrades mRNA with Nonsense Codons. FEBS Lett, Vol. 581, No. 15, (Jun 2007), pp. 28452853, ISSN 0014-5793 
Belbin, T. J., Singh, B., Barber, I., Socci, N., Wenig, B., Smith, R., Prystowsky, M. B., \& Childs, G. (2002). Molecular Classification of Head and Neck Squamous Cell Carcinoma Using cDNA Microarrays. Cancer Res, Vol. 62, No. 4, (Feb 2002), pp. 1184-1190, ISSN 0008-5472

Blons, H., \& Laurent-Puig, P. (2003). TP53 and Head and Neck Neoplasms. Hum Mutat, Vol. 21, No. 3, (Mar 2003), pp. 252-257, ISSN 1098-1004

Boyle, J. O., Hakim, J., Koch, W., Van der Riet, P., Hruban, R. H., Roa, R. A., Correo, R., Eby, Y. J., Ruppert, J. M., \& Sidransky, D. (1993). The Incidence of p53 Mutations Increases with Progression of Head and Neck Cancer. Cancer Res, Vol. 53, No. 19, (Oct 1993), pp. 4477-4480, ISSN 0008-5472

Braakhuis, B. J., Senft, A., de Bree, R., de Vries, J., Ylstra, B., Cloos, J., Kuik, D. J., Leemans, C. R., \& Brakenhoff, R. H. (2006). Expression Profiling and Prediction of Distant Metastases in Head and Neck Squamous Cell Carcinoma. J Clin Pathol, Vol. 59, No. 12, (Dec 2006), pp. 1254-1260, ISSN 0021-9746

Braakhuis, B. J., Tabor, M. P., Kummer, J. A., Leemans, C. R., \&Brakenhoff, R. H. (2003). A Genetic Explanation of Slaughter's Concept of Field Cancerization: Evidence and Clinical Implications. Cancer Res, Vol. 63, No. 8, (Apr 2003), pp. 1727-1730, ISSN 0008-5472

Bradford, C. R., Zhu, S., Ogawa, H., Ogawa, T., Ubell, M., Narayan, A., Johnson, G., Wolf, G. T., Fisher, S. G., \& Carey, T. E. (2003). p53 Mutation Correlates with Cisplatin Sensitivity in Head and Neck Squamous Cell Carcinoma Lines. Head Neck, Vol. 25, No. 8, (Aug 2003), pp. 654-661, ISSN 1043-3074

Cabanillas, R., Rodrigo, J. P., Astudillo, A., Dominguez, F., Suarez, C., \& Chiara, M. D. (2007). p53 Expression in Squamous Cell Carcinomas of the Supraglottic Larynx and Its Lymph Node Metastases: New Results for an Old Question. Cancer, Vol. 109, No. 9, (May 2007), pp. 1791-1798, ISSN 0008-543X

Cabelguenne, A., Blons, H., de Waziers, I., Carnot, F., Houllier, A. M., Soussi, T., Brasnu, D., Beaune, P., Laccourreye, O., \& Laurent-Puig, P. (2000). p53 Alterations Predict Tumor Response to Neoadjuvant Chemotherapy in Head and Neck Squamous Cell Carcinoma: A Prospective Series. J Clin Oncol, Vol. 18, No. 7, (Apr 2000), pp. 14651473, ISSN 0732-183X

Califano, J., van der Riet, P., Westra, W., Nawroz, H., Clayman, G., Piantadosi, S., Corio, R., Lee, D., Greenberg, B., Koch, W., \& Sidransky, D. (1996). Genetic Progression Model for Head and Neck Cancer: Implications for Field Cancerization. Cancer Res, Vol. 56, No. 11, (Jun 1996), pp. 2488-2492, ISSN 0008-5472

Califano, J., Westra, W. H., Meininger, G., Corio, R., Koch, W. M., \& Sidransky, D. (2000). Genetic Progression and Clonal Relationship of Recurrent Premalignant Head and Neck Lesions. Clin Cancer Res, Vol. 6, No. 2, (Feb 2000), pp. 347-352, ISSN 1078-0432

Capaccio, P., Pruneri, G., Carboni, N., Pagliari, A. V., Quatela, M., Cesana, B. M., \& Pignataro, L. (2000). Cyclin D1 Expression Is Predictive of Occult Metastases in Head and Neck Cancer Patients with Clinically Negative Cervical Lymph Nodes. Head Neck, Vol. 22, No. 3, (May 2000), pp. 234-240, ISSN 1043-3074

Carracedo, D. G., Astudillo, A., Rodrigo, J. P., Suarez, C., \& Gonzalez, M. V. (2008). Skp2, P27kip1 and Egfr Assessment in Head and Neck Squamous Cell Carcinoma: Prognostic Implications. Oncol Rep, Vol. 20, No. 3, (Sep 2008), pp. 589-595, ISSN 1021-335X 
Casse, C., Hu, Y. C., \& Ahrendt, S. A. (2003). The Xrcc1 Codon 399 Gln Allele Is Associated with Adenine to Guanine p53 Mutations in Non-Small Cell Lung Cancer. Mutat Res, Vol. 528, No. 1-2, (Jul 2003), pp. 19-27, ISSN 0027-5107

Cervigne, N. K., Reis, P. P., Machado, J., Sadikovic, B., Bradley, G., Galloni, N. N., Pintilie, M., Jurisica, I., Perez-Ordonez, B., Gilbert, R., Gullane, P., Irish, J., \& Kamel-Reid, S. (2009). Identification of a MicroRNA Signature Associated with Progression of Leukoplakia to Oral Carcinoma. Hum Mol Genet, Vol. 18, No. 24, (Dec 2009), pp. 4818-4829, ISSN 1460-2083

Chang, C. J., Hsu, C. C., Chang, C. H., Tsai, L. L., Chang, Y. C., Lu, S. W., Yu, C. H., Huang, H. S., Wang, J. J., Tsai, C. H., Chou, M. Y., Yu, C. C., \& Hu, F. W. (2011). Let-7d Functions as Novel Regulator of Epithelial-Mesenchymal Transition and Chemoresistant Property in Oral Cancer. Oncol Rep, Vol. 26, No. 4, (Oct 2011), pp. 1003-1010, ISSN 1791-2431

Chang, K. W., Liu, C. J., Chu, T. H., Cheng, H. W., Hung, P. S., Hu, W. Y., \& Lin, S. C. (2008). Association between High Mir-211 MicroRNA Expression and the Poor Prognosis of Oral Carcinoma. J Dent Res, Vol. 87, No. 11, (Nov 2008), pp. 1063-1068, ISSN 1544-0591

Chang, S. S., \& Califano, J. (2008). Current Status of Biomarkers in Head and Neck Cancer. J Surg Oncol, Vol. 97, No. 8, (Jun 2008), pp. 640-643, ISSN 0022-4790

Chang, S. S., Jiang, W. W., Smith, I., Poeta, L. M., Begum, S., Glazer, C., Shan, S., Westra, W., Sidransky, D., \& Califano, J. A. (2008). MicroRNA Alterations in Head and Neck Squamous Cell Carcinoma. Int J Cancer, Vol. 123, No. 12, (Dec 2008), pp. 2791-2797, ISSN 1097-0215

Chen, H. C., Chen, G. H., Chen, Y. H., Liao, W. L., Liu, C. Y., Chang, K. P., Chang, Y. S., \& Chen, S. J. (2009). MicroRNA Deregulation and Pathway Alterations in Nasopharyngeal Carcinoma. Br J Cancer, Vol. 100, No. 6, (Mar 2009), pp. 1002-1011, ISSN 1532-1827

Chen, L. H., Tsai, K. L., Chen, Y. W., Yu, C. C., Chang, K. W., Chiou, S. H., Ku, H. H., Chu, P. Y., Tseng, L. M., Huang, P. I., \& Lo, W. L. (2010). MicroRNA as a Novel Modulator in Head and Neck Squamous Carcinoma. J Oncol, Vol. 2010, No., (Feb 2010), pp. 135632, ISSN 1687-8469

Chen, Y., \& Chen, C. (2008). DNA Copy Number Variation and Loss of Heterozygosity in Relation to Recurrence of and Survival from Head and Neck Squamous Cell Carcinoma: A Review. Head Neck, Vol. 30, No. 10, (Oct 2008), pp. 1361-1383, ISSN 1097-0347

Childs, G., Fazzari, M., Kung, G., Kawachi, N., Brandwein-Gensler, M., McLemore, M., Chen, Q., Burk, R. D., Smith, R. V., Prystowsky, M. B., Belbin, T. J., \& Schlecht, N. F. (2009). Low-Level Expression of MicroRNAs Let-7d and Mir-205 Are Prognostic Markers of Head and Neck Squamous Cell Carcinoma. Am J Pathol, Vol. 174, No. 3, (Mar 2009), pp. 736-745, ISSN 1525-2191

Choi, P., \& Chen, C. (2005). Genetic Expression Profiles and Biologic Pathway Alterations in Head and Neck Squamous Cell Carcinoma. Cancer, Vol. 104, No. 6, (Sep 2005), pp. 1113-1128, ISSN 0008-543X

Chung, C. H., \& Gillison, M. L. (2009). Human Papillomavirus in Head and Neck Cancer: Its Role in Pathogenesis and Clinical Implications. Clin Cancer Res, Vol. 15, No. 22, (Nov 2009), pp. 6758-6762, ISSN 1078-0432 
Chung, C. H., Parker, J. S., Karaca, G., Wu, J., Funkhouser, W. K., Moore, D., Butterfoss, D., Xiang, D., Zanation, A., Yin, X., Shockley, W. W., Weissler, M. C., Dressler, L. G., Shores, C. G., Yarbrough, W. G., \& Perou, C. M. (2004). Molecular Classification of Head and Neck Squamous Cell Carcinomas Using Patterns of Gene Expression. Cancer Cell, Vol. 5, No. 5, (May 2004), pp. 489-500, ISSN 1535-6108

Cruz, I. B., Snijders, P. J., Meijer, C. J., Braakhuis, B. J., Snow, G. B., Walboomers, J. M., \& van der Waal, I. (1998). P53 Expression above the Basal Cell Layer in Oral Mucosa Is an Early Event of Malignant Transformation and Has Predictive Value for Developing Oral Squamous Cell Carcinoma. J Pathol, Vol. 184, No. 4, (Apr 1998), pp. 360-368, ISSN 0022-3417

D'Souza, G., Kreimer, A. R., Viscidi, R., Pawlita, M., Fakhry, C., Koch, W. M., Westra, W. H., \& Gillison, M. L. (2007). Case-Control Study of Human Papillomavirus and Oropharyngeal Cancer. N Engl J Med, Vol. 356, No. 19, (May 2007), pp. 1944-1956, ISSN 1533-4406

Eling, T. E., Thompson, D. C., Foureman, G. L., Curtis, J. F., \& Hughes, M. F. (1990). Prostaglandin H Synthase and Xenobiotic Oxidation. Annu Rev Pharmacol Toxicol, Vol. 30, No., (Apr 1990), pp. 1-45, ISSN 0362-1642

Esteller, M., \& Herman, J. G. (2002). Cancer as an Epigenetic Disease: DNA Methylation and Chromatin Alterations in Human Tumours. J Pathol, Vol. 196, No. 1, (Jan 2002), pp. 1-7, ISSN 0022-3417

Ferlito, A., Shaha, A. R., Silver, C. E., Rinaldo, A., \& Mondin, V. (2001). Incidence and Sites of Distant Metastases from Head and Neck Cancer. ORL J OtorhinolaryngolRelat Spec, Vol. 63, No. 4, (Jul-Aug 2001), pp. 202-207, ISSN 0301-1569

Field, J. K., Spandidos, D. A., Malliri, A., Gosney, J. R., Yiagnisis, M., \& Stell, P. M. (1991). Elevated p53 Expression Correlates with a History of Heavy Smoking in Squamous Cell Carcinoma of the Head and Neck. Br J Cancer, Vol. 64, No. 3, (Sep 1991), pp. 573-577, ISSN 0007-0920

Fletcher, A. M., Heaford, A. C., \& Trask, D. K. (2008). Detection of Metastatic Head and Neck Squamous Cell Carcinoma Using the Relative Expression of Tissue-Specific Mir-205. Transl Oncol, Vol. 1, No. 4, (Dec 2008), pp. 202-208, ISSN 1936-5233

Fu, X., Han, Y., Wu, Y., Zhu, X., Lu, X., Mao, F., Wang, X., He, X., \& Zhao, Y. (2011). Prognostic Role of MicroRNA-21 in Various Carcinomas: A Systematic Review and Meta-Analysis. Eur J Clin Invest, Vol., No., (Apr 2011), pp., ISSN 1365-2362

Gallo, O., Franchi, A., Magnelli, L., Sardi, I., Vannacci, A., Boddi, V., Chiarugi, V., \& Masini, E. (2001). Cyclooxygenase-2 Pathway Correlates with Vegf Expression in Head and Neck Cancer. Implications for Tumor Angiogenesis and Metastasis. Neoplasia, Vol. 3, No. 1, (Jan-Feb 2001), pp. 53-61, ISSN 1522-8002

Gallo, O., Masini, E., Bianchi, B., Bruschini, L., Paglierani, M., \& Franchi, A. (2002). Prognostic Significance of Cyclooxygenase-2 Pathway and Angiogenesis in Head and Neck Squamous Cell Carcinoma. Hum Pathol, Vol. 33, No. 7, (Jul 2002), pp. 708714, ISSN 0046-8177

Ganci, F., Conti, S., Fontemaggi, G., Manciocco, V., Donzelli, S., Covello, R., Muti, P., Strano, S., Blandino, G., \& Spriano, G. (2011). Allelic Expression Imbalance of TP53 Mutated and Polymorphic Alleles in Head and Neck Tumors. OMICS, Vol. 15, No. 6, (Jun 2011), pp. 375-381, ISSN 1557-8100 
Ganly, I., Talbot, S., Carlson, D., Viale, A., Maghami, E., Osman, I., Sherman, E., Pfister, D., Chuai, S., Shaha, A. R., Kraus, D., Shah, J. P., Socci, N. D., \& Singh, B. (2007). Identification of Angiogenesis/Metastases Genes Predicting Chemoradiotherapy Response in Patients with Laryngopharyngeal Carcinoma. J Clin Oncol, Vol. 25, No. 11, (Apr 2007), pp. 1369-1376, ISSN 1527-7755

Garavello, W., Foschi, R., Talamini, R., La Vecchia, C., Rossi, M., Dal Maso, L., Tavani, A., Levi, F., Barzan, L., Ramazzotti, V., Franceschi, S., \& Negri, E. (2008). Family History and the Risk of Oral and Pharyngeal Cancer. Int J Cancer, Vol. 122, No. 8, (Apr 2008), pp. 1827-1831, ISSN 1097-0215

Gasco, M., \& Crook, T. (2003). The p53 Network in Head and Neck Cancer. Oral Oncol, Vol. 39, No. 3, (Apr 2003), pp. 222-231, ISSN 1368-8375

Gee, H. E., Camps, C., Buffa, F. M., Patiar, S., Winter, S. C., Betts, G., Homer, J., Corbridge, R., Cox, G., West, C. M., Ragoussis, J., \& Harris, A. L. (2010). Hsa-Mir-210 Is a Marker of Tumor Hypoxia and a Prognostic Factor in Head and Neck Cancer. Cancer, Vol. 116, No. 9, (May 2010), pp. 2148-2158, ISSN 0008-543X

Glazer, C. A., Chang, S. S., Ha, P. K., \& Califano, J. A. (2009). Applying the Molecular Biology and Epigenetics of Head and Neck Cancer in Everyday Clinical Practice. Oral Oncol, Vol. 45, No. 4-5, (Apr-May 2009), pp. 440-446, ISSN 1368-8375

Gottlieb, E., \& Tomlinson, I. P. (2005). Mitochondrial Tumour Suppressors: A Genetic and Biochemical Update. Nat Rev Cancer, Vol. 5, No. 11, (Nov 2005), pp. 857-866, ISSN 1474-175X

Grandis, J. R., \& Tweardy, D. J. (1993). Elevated Levels of Transforming Growth Factor Alpha and Epidermal Growth Factor Receptor Messenger RNA Are Early Markers of Carcinogenesis in Head and Neck Cancer. Cancer Res, Vol. 53, No. 15, (Aug 1993), pp. 3579-3584, ISSN 0008-5472

Graveland, A. P., Golusinski, P. J., Buijze, M., Douma, R., Sons, N., Kuik, D. J., Bloemena, E., Leemans, C. R., Brakenhoff, R. H., \& Braakhuis, B. J. (2011). Loss of Heterozygosity at $9 \mathrm{p}$ and p53 Immunopositivity in Surgical Margins Predict Local Relapse in Head and Neck Squamous Cell Carcinoma. Int J Cancer, Vol. 128, No. 8, (Apr 2011), pp. 1852-1859, ISSN 1097-0215

Ha, P. K., \& Califano, J. A. (2003). The Molecular Biology of Mucosal Field Cancerization of the Head and Neck. Crit Rev Oral Biol Med, Vol. 14, No. 5, (Sep 2003), pp. 363-369, ISSN 1544-1113

Ha, P. K., \& Califano, J. A. (2006). Promoter Methylation and Inactivation of TumourSuppressor Genes in Oral Squamous-Cell Carcinoma. Lancet Oncol, Vol. 7, No. 1, (Jan 2006), pp. 77-82, ISSN 1470-2045

Ha, P. K., Chang, S. S., Glazer, C. A., Califano, J. A., \& Sidransky, D. (2009). Molecular Techniques and Genetic Alterations in Head and Neck Cancer. Oral Oncol, Vol. 45, No. 4-5, (Apr-May 2009), pp. 335-339, ISSN 1368-8375

Hama, T., Yuza, Y., Saito, Y., J, O. uchi, Kondo, S., Okabe, M., Yamada, H., Kato, T., Moriyama, H., Kurihara, S., \& Urashima, M. (2009). Prognostic Significance of Epidermal Growth Factor Receptor Phosphorylation and Mutation in Head and Neck Squamous Cell Carcinoma. Oncologist, Vol. 14, No. 9, (Sep 2009), pp. 900-908, ISSN 1549-490X

Henson, B. J., Bhattacharjee, S., O'Dee, D. M., Feingold, E., \& Gollin, S. M. (2009). Decreased Expression of Mir-125b and Mir-100 in Oral Cancer Cells Contributes to 
Malignancy. Genes Chromosomes Cancer, Vol. 48, No. 7, (Jul 2009), pp. 569-582, ISSN 1098-2264

Herman, J. G., \& Baylin, S. B. (2003). Gene Silencing in Cancer in Association with Promoter Hypermethylation. N Engl J Med, Vol. 349, No. 21, (Nov 2003), pp. 2042-2054, ISSN 1533-4406

Holley, S. L., Matthias, C., Jahnke, V., Fryer, A. A., Strange, R. C., \& Hoban, P. R. (2005). Association of Cyclin D1 Polymorphism with Increased Susceptibility to Oral Squamous Cell Carcinoma. Oral Oncol, Vol. 41, No. 2, (Feb 2005), pp. 156-160, ISSN 1368-8375

Huber, G. F., Fritzsche, F. R., Zullig, L., Storz, M., Graf, N., S, K. Haerle, Jochum, W., Stoeckli, S. J., \& Moch, H. (2011). Podoplanin Expression Correlates with Sentinel Lymph Node Metastasis in Early Squamous Cell Carcinomas of the Oral Cavity and Oropharynx. Int J Cancer, Vol. 129, No. 6, (Sep 2011), pp. 1404-1409, ISSN 10970215

Huber, G. F., Zullig, L., Soltermann, A., Roessle, M., Graf, N., Haerle, S. K., Studer, G., Jochum, W., Moch, H., \&Stoeckli, S. J. (2011). Down Regulation of E-Cadherin (Ecad) - a Predictor for Occult Metastatic Disease in Sentinel Node Biopsy of Early Squamous Cell Carcinomas of the Oral Cavity and Oropharynx. BMC Cancer, Vol. 11, No.,(June 2011), pp. 217, ISSN 1471-2407

Hui, A. B., Lenarduzzi, M., Krushel, T., Waldron, L., Pintilie, M., Shi, W., Perez-Ordonez, B., Jurisica, I., O'Sullivan, B., Waldron, J., Gullane, P., Cummings, B., \& Liu, F. F. (2010). Comprehensive MicroRNA Profiling for Head and Neck Squamous Cell Carcinomas. Clin Cancer Res, Vol. 16, No. 4, (Feb 2010), pp. 1129-1139, ISSN 10780432

Hussain, S. P., \& Harris, C. C. (1999). p53 Mutation Spectrum and Load: The Generation of Hypotheses Linking the Exposure of Endogenous or Exogenous Carcinogens to Human Cancer. Mutat Res, Vol. 428, No. 1-2, (Jul 1999), pp. 23-32, ISSN 0027-5107

Ingelman-Sundberg, M. (2001). Genetic Variability in Susceptibility and Response to Toxicants. Toxicol Lett, Vol. 120, No. 1-3, (Mar 2001), pp. 259-268, ISSN 0378-4274

Itoh, S., Matsui, K., Furuta, I., \& Takano, Y. (2003). Immunohistochemical Study on Overexpression of Cyclooxygenase-2 in Squamous Cell Carcinoma of the Oral Cavity: Its Importance as a Prognostic Predictor. Oral Oncol, Vol. 39, No. 8, (Dec 2003), pp. 829-835, ISSN 1368-8375

Ivanovska, I., Ball, A. S., Diaz, R. L., Magnus, J. F., Kibukawa, M., Schelter, J. M., Kobayashi, S. V., Lim, L., Burchard, J., Jackson, A. L., Linsley, P. S., \& Cleary, M. A. (2008). MicroRNAs in the Mir-106b Family Regulate P21/Cdkn1a and Promote Cell Cycle Progression. Mol Cell Biol, Vol. 28, No. 7, (Apr 2008), pp. 2167-2174, ISSN 1098-5549

Izzo, J. G., Papadimitrakopoulou, V. A., Li, X. Q., Ibarguen, H., Lee, J. S., Ro, J. Y., El-Naggar, A., Hong, W. K., \& Hittelman, W. N. (1998). Dysregulated Cyclin D1 Expression Early in Head and Neck Tumorigenesis: In Vivo Evidence for an Association with Subsequent Gene Amplification. Oncogene, Vol. 17, No. 18, (Nov 1998), pp. 23132322, ISSN 0950-9232

Jamieson, T. A., Brizel, D. M., Killian, J. K., Oka, Y., Jang, H. S., Fu, X., Clough, R. W., Vollmer, R. T., Anscher, M. S., \&Jirtle, R. L. (2003). M6p/Igf2r Loss of Heterozygosity in Head and Neck Cancer Associated with Poor Patient Prognosis. BMC Cancer, Vol. 3, No., (Feb 2003), pp. 4, ISSN 1471-2407 
Kalyankrishna, S., \& Grandis, J. R. (2006). Epidermal Growth Factor Receptor Biology in Head and Neck Cancer. J Clin Oncol, Vol. 24, No. 17, (Jun 2006), pp. 2666-2672, ISSN 1527-7755

Kearsley, J. H., Furlong, K. L., Cooke, R. A., \& Waters, M. J. (1990). An Immunohistochemical Assessment of Cellular Proliferation Markers in Head and Neck Squamous Cell Cancers. Br J Cancer, Vol. 61, No. 6, (Jun 1990), pp. 821-827, ISSN 0007-0920

Kimura, S., Naganuma, S., Susuki, D., Hirono, Y., Yamaguchi, A., Fujieda, S., Sano, K., \& Itoh, H. (2010). Expression of MicroRNAs in Squamous Cell Carcinoma of Human Head and Neck and the Esophagus: Mir-205 and Mir-21 Are Specific Markers for HNSCC and Escc. Oncol Rep, Vol. 23, No. 6, (Jun 2010), pp. 1625-1633, ISSN 17912431

Kiuru, A., Servomaa, K., Grenman, R., Pulkkinen, J., \& Rytomaa, T. (1997). p53 Mutations in Human Head and Neck Cancer Cell Lines. Acta Otolaryngol Suppl, Vol. 529, No., (1997), pp. 237-240, ISSN 0365-5237

Ko, Y., Abel, J., Harth, V., Brode, P., Antony, C., Donat, S., Fischer, H. P., Ortiz-Pallardo, M. E., Thier, R., Sachinidis, A., Vetter, H., Bolt, H. M., Herberhold, C., \& Bruning, T. (2001). Association of Cyp1b1 Codon 432 Mutant Allele in Head and Neck Squamous Cell Cancer Is Reflected by Somatic Mutations of p53 in Tumor Tissue. Cancer Res, Vol. 61, No. 11, (Jun 2001), pp. 4398-4404, ISSN 0008-5472

Kojima, M., Morisaki, T., Uchiyama, A., Doi, F., Mibu, R., Katano, M., \& Tanaka, M. (2001). Association of Enhanced Cyclooxygenase-2 Expression with Possible Local Immunosuppression in Human Colorectal Carcinomas. Ann Surg Oncol, Vol. 8, No. 5, (Jun 2001), pp. 458-465, ISSN 1068-9265

Kozaki, K., Imoto, I., Mogi, S., Omura, K., \& Inazawa, J. (2008). Exploration of TumorSuppressive MicroRNAs Silenced by DNA Hypermethylation in Oral Cancer. Cancer Res, Vol. 68, No. 7, (Apr 2008), pp. 2094-2105, ISSN 1538-7445

Kumar, R. V., Kadkol, S. S., Daniel, R., Shenoy, A. M., \& Shah, K. V. (2003). Human Papillomavirus, p53 and Cyclin D1 Expression in Oropharyngeal Carcinoma. Int J Oral MaxillofacSurg, Vol. 32, No. 5, (Oct 2003), pp. 539-543, ISSN 0901-5027

Kusukawa, J., Harada, H., Shima, I., Sasaguri, Y., Kameyama, T., \& Morimatsu, M. (1996). The Significance of Epidermal Growth Factor Receptor and Matrix Metalloproteinase-3 in Squamous Cell Carcinoma of the Oral Cavity. Eur J Cancer B Oral Oncol, Vol. 32B, No. 4, (Jul 1996), pp. 217-221, ISSN 0964-1955

Kyzas, P. A., Cunha, I. W., \& Ioannidis, J. P. (2005). Prognostic Significance of Vascular Endothelial Growth Factor Immunohistochemical Expression in Head and Neck Squamous Cell Carcinoma: A Meta-Analysis. Clin Cancer Res, Vol. 11, No. 4, (Feb 2005), pp. 1434-1440, ISSN 1078-0432

Kyzas, P. A., Stefanou, D., \& Agnantis, N. J. (2004). Immunohistochemical Expression of Vascular Endothelial Growth Factor Correlates with Positive Surgical Margins and Recurrence in T1 and T2 Squamous Cell Carcinoma (Scc) of the Lower Lip. Oral Oncol, Vol. 40, No. 9, (Oct 2004), pp. 941-947, ISSN 1368-8375

Lacko, M., Oude Ophuis, M. B., Peters, W. H., \& Manni, J. J. (2009). Genetic Polymorphisms of Smoking-Related Carcinogen Detoxifying Enzymes and Head and Neck Cancer Susceptibility. Anticancer Res, Vol. 29, No. 2, (Feb 2009), pp. 753-761, ISSN 0250-7005 
Lajer, C. B., Nielsen, F. C., Friis-Hansen, L., Norrild, B., Borup, R., Garnaes, E., Rossing, M., Specht, L., Therkildsen, M. H., Nauntofte, B., Dabelsteen, S., \& von Buchwald, C. (2011). Different MirRNA Signatures of Oral and Pharyngeal Squamous Cell Carcinomas: A Prospective Translational Study. Br J Cancer, Vol. 104, No. 5, (Mar 2011), pp. 830-840, ISSN 1532-1827

Lallemant, B., Evrard, A., Chambon, G., Sabra, O., Kacha, S., Lallemant, J. G., Lumbroso, S., \& Brouillet, J. P. (2010). Gene Expression Profiling in Head and Neck Squamous Cell Carcinoma: Clinical Perspectives. Head Neck, Vol. 32, No. 12, (Dec 2010), pp. 1712-1719, ISSN 1097-0347

Langevin, S. M., Stone, R. A., Bunker, C. H., Grandis, J. R., Sobol, R. W., \&Taioli, E. (2010). MicroRNA-137 Promoter Methylation in Oral Rinses from Patients with Squamous Cell Carcinoma of the Head and Neck Is Associated with Gender and Body Mass Index. Carcinogenesis, Vol. 31, No. 5, (May 2010), pp. 864-870, ISSN 1460-2180

Langevin, S. M., Stone, R. A., Bunker, C. H., Lyons-Weiler, M. A., Laframboise, W. A., Kelly, L., Seethala, R. R., Grandis, J. R., Sobol, R. W., \&Taioli, E. (2010). MicroRNA-137 Promoter MethylationIs Associated with Poorer Overall Survival in Patients with Squamous Cell Carcinoma of the Head and Neck. Cancer, Vol., No., (Nov 2010), pp., ISSN 0008-543X

Lassaletta, L., Brandariz, J. A., Benito, A., de la Cruz, J., Gomez, C., Ballestin, C., Hitt, R., Colomer, R., \& Alvarez-Vicent, J. J. (1999). p53 Expression in Locally Advanced Pharyngeal Squamous Cell Carcinoma. Arch Otolaryngol Head Neck Surg, Vol. 125, No. 12, (Dec 1999), pp. 1356-1359, ISSN 0886-4470

Lee, J. I., Soria, J. C., Hassan, K., Liu, D., Tang, X., El-Naggar, A., Hong, W. K., \& Mao, L. (2001). Loss of Fhit Expression Is a Predictor of Poor Outcome in Tongue Cancer. Cancer Res, Vol. 61, No. 3, (Feb 2001), pp. 837-841, ISSN 0008-5472

Lee, J. J., Hong, W. K., Hittelman, W. N., Mao, L., Lotan, R., Shin, D. M., Benner, S. E., Xu, X. C., Lee, J. S., Papadimitrakopoulou, V. M., Geyer, C., Perez, C., Martin, J. W., ElNaggar, A. K., \&Lippman, S. M. (2000). Predicting Cancer Development in Oral Leukoplakia: Ten Years of Translational Research. Clin Cancer Res, Vol. 6, No. 5, (May 2000), pp. 1702-1710, ISSN 1078-0432

Lee, Y., Yang, X., Huang, Y., Fan, H., Zhang, Q., Wu, Y., Li, J., Hasina, R., Cheng, C., Lingen, M. W., Gerstein, M. B., Weichselbaum, R. R., Xing, H. R., \&Lussier, Y. A. (2010). Network Modeling Identifies Molecular Functions Targeted by Mir-204 to Suppress Head and Neck Tumor Metastasis. PLoS Comput Biol, Vol. 6, No. 4, (Apr 2010), pp. e1000730, ISSN 1553-7358

Leemans, C. R., Braakhuis, B. J., \& Brakenhoff, R. H. (2011). The Molecular Biology of Head and Neck Cancer. Nat Rev Cancer, Vol. 11, No. 1, (Jan 2011), pp. 9-22, ISSN 14741768

Lentsch, E. J., Goudy, S., Sosnowski, J., Major, S., \&Bumpous, J. M. (2006). Microvessel Density in Head and Neck Squamous Cell Carcinoma Primary Tumors and Its Correlation with Clinical Staging Parameters. Laryngoscope, Vol. 116, No. 3, (Mar 2006), pp. 397-400, ISSN 0023-852X

Li, C., Hu, Z., Lu, J., Liu, Z., Wang, L. E., El-Naggar, A. K., Sturgis, E. M., Spitz, M. R., \& Wei, Q. (2007). Genetic Polymorphisms in DNA Base-Excision Repair Genes Adprt, Xrcc1, and Ape1 and the Risk of Squamous Cell Carcinoma of the Head and Neck. Cancer, Vol. 110, No. 4, (Aug 2007), pp. 867-875, ISSN 0008-543X 
Li, Y., Elashoff, D., Oh, M., Sinha, U., St John, M. A., Zhou, X., Abemayor, E., \& Wong, D. T. (2006). Serum Circulating Human Mrna Profiling and Its Utility for Oral Cancer Detection. J Clin Oncol, Vol. 24, No. 11, (Apr 2006), pp. 1754-1760, ISSN 1527-7755

Li, Z., Guan, W., Li, M. X., Zhong, Z. Y., Qian, C. Y., Yang, X. Q., Liao, L., Li, Z. P., \& Wang, D. (2011). Genetic Polymorphism of DNA Base-Excision Repair Genes (Ape1, Ogg1 and Xrcc1) and Their Correlation with Risk of Lung Cancer in a Chinese Population. Arch Med Res, Vol. 42, No. 3, (Apr 2011), pp. 226-234, ISSN 1873-5487

Lim, S. C. (2005). Expression of C-Erbb Receptors, Mmps and Vegf in Head and Neck Squamous Cell Carcinoma. Biomed Pharmacother, Vol. 59 Suppl 2, No., (Oct 2005), pp. S366-369, ISSN 0753-3322

Lin, C. C., Liu, L. Z., Addison, J. B., Wonderlin, W. F., Ivanov, A. V., \&Ruppert, J. M. (2011). A Klf4-Mirna-206 Autoregulatory Feedback Loop Can Promote or Inhibit Protein Translation Depending Upon Cell Context. Mol Cell Biol, Vol. 31, No. 12, (Jun 2011), pp. 2513-2527, ISSN 1098-5549

Lin, D. T., Subbaramaiah, K., Shah, J. P., Dannenberg, A. J., \& Boyle, J. O. (2002). Cyclooxygenase-2: A Novel Molecular Target for the Prevention and Treatment of Head and Neck Cancer. Head Neck, Vol. 24, No. 8, (Aug 2002), pp. 792-799, ISSN 1043-3074

Liu, C. J., Kao, S. Y., Tu, H. F., Tsai, M. M., Chang, K. W., \& Lin, S. C. (2010). Increase of MicroRNA Mir-31 Level in Plasma Could Be a Potential Marker of Oral Cancer. Oral Dis, Vol. 16, No. 4, (May 2010), pp. 360-364, ISSN 1601-0825

Liu, C. J., Tsai, M. M., Hung, P. S., Kao, S. Y., Liu, T. Y., Wu, K. J., Chiou, S. H., Lin, S. C., \& Chang, K. W. (2010). Mir-31 Ablates Expression of the Hif Regulatory Factor Fih to Activate the Hif Pathway in Head and Neck Carcinoma. Cancer Res, Vol. 70, No. 4, (Feb 2010), pp. 1635-1644, ISSN 1538-7445

Liu, X., Jiang, L., Wang, A., Yu, J., Shi, F., \& Zhou, X. (2009). MicroRNA-138 Suppresses Invasion and Promotes Apoptosis in Head and Neck Squamous Cell Carcinoma Cell Lines. Cancer Lett, Vol. 286, No. 2, (Dec 2009), pp. 217-222, ISSN 1872-7980

Llewellyn, C. D., Johnson, N. W., \& Warnakulasuriya, S. (2004). Factors Associated with Delay in Presentation among Younger Patients with Oral Cancer. Oral Surg Oral Med Oral Pathol Oral Radiol Endod, Vol. 97, No. 6, (Jun 2004), pp. 707-713, ISSN 10792104

Llewellyn, C. D., Linklater, K., Bell, J., Johnson, N. W., \& Warnakulasuriya, S. (2004). An Analysis of Risk Factors for Oral Cancer in Young People: A Case-Control Study. Oral Oncol, Vol. 40, No. 3, (Mar 2004), pp. 304-313, ISSN 1368-8375

Logullo, A. F., Nonogaki, S., Miguel, R. E., Kowalski, L. P., Nishimoto, I. N., Pasini, F. S., Federico, M. H., Brentani, R. R., \& Brentani, M. M. (2003). Transforming Growth Factor Beta1 (Tgfbeta1) Expression in Head and Neck Squamous Cell Carcinoma Patients as Related to Prognosis. J Oral Pathol Med, Vol. 32, No. 3, (Mar 2003), pp. 139-145, ISSN 0904-2512

Long, X. B., Sun, G. B., Hu, S., Liang, G. T., Wang, N., Zhang, X. H., Cao, P. P., Zhen, H. T., Cui, Y. H., \& Liu, Z. (2009). Let-7a MicroRNA Functions as a Potential Tumor Suppressor in Human Laryngeal Cancer. Oncol Rep, Vol. 22, No. 5, (Nov 2009), pp. 1189-1195, ISSN 1021-335X

Lopez, M., Aguirre, J. M., Cuevas, N., Anzola, M., Videgain, J., Aguirregaviria, J., \& Martinez de Pancorbo, M. (2003). Gene Promoter Hypermethylation in Oral Rinses 
of Leukoplakia Patients-a Diagnostic and/or Prognostic Tool? Eur J Cancer, Vol. 39, No. 16, (Nov 2003), pp. 2306-2309, ISSN 0959-8049

Marsit, C. J., Black, C. C., Posner, M. R., \& Kelsey, K. T. (2008). A Genotype-Phenotype Examination of Cyclin D1 on Risk and Outcome of Squamous Cell Carcinoma of the Head and Neck. Clin Cancer Res, Vol. 14, No. 8, (Apr 2008), pp. 2371-2377, ISSN 1078-0432

Marsit, C. J., Christensen, B. C., Houseman, E. A., Karagas, M. R., Wrensch, M. R., Yeh, R. F., Nelson, H. H., Wiemels, J. L., Zheng, S., Posner, M. R., McClean, M. D., Wiencke, J. K., \& Kelsey, K. T. (2009). Epigenetic Profiling Reveals Etiologically Distinct Patterns of DNA Methylation in Head and Neck Squamous Cell Carcinoma. Carcinogenesis, Vol. 30, No. 3, (Mar 2009), pp. 416-422, ISSN 1460-2180

Marsit, C. J., McClean, M. D., Furniss, C. S., \& Kelsey, K. T. (2006). Epigenetic Inactivation of the Sfrp Genes Is Associated with Drinking, Smoking and Hpv in Head and Neck Squamous Cell Carcinoma. Int J Cancer, Vol. 119, No. 8, (Oct 2006), pp. 1761-1766, ISSN 0020-7136

Matlashewski, G. J., Tuck, S., Pim, D., Lamb, P., Schneider, J., \& Crawford, L. V. (1987). Primary Structure Polymorphism at Amino Acid Residue 72 of Human p53. Mol Cell Biol, Vol. 7, No. 2, (Feb 1987), pp. 961-963, ISSN 0270-7306

Mehlen, P., \& Puisieux, A. (2006). Metastasis: A Question of Life or Death. Nat Rev Cancer, Vol. 6, No. 6, (Jun 2006), pp. 449-458, ISSN 1474-175X

Michalides, R. J., van Veelen, N. M., Kristel, P. M., Hart, A. A., Loftus, B. M., Hilgers, F. J., \& Balm, A. J. (1997). Overexpression of Cyclin D1 Indicates a Poor Prognosis in Squamous Cell Carcinoma of the Head and Neck. Arch Otolaryngol Head Neck Surg, Vol. 123, No. 5, (May 1997), pp. 497-502, ISSN 0886-4470

Mineta, H., Miura, K., Ogino, T., Takebayashi, S., Misawa, K., Ueda, Y., Suzuki, I., Dictor, M., Borg, A., \& Wennerberg, J. (2000). Prognostic Value of Vascular Endothelial Growth Factor (Vegf) in Head and Neck Squamous Cell Carcinomas. Br J Cancer, Vol. 83, No. 6, (Sep 2000), pp. 775-781, ISSN 0007-0920

Mineta, H., Miura, K., Takebayashi, S., Misawa, K., Ueda, Y., Suzuki, I., Ito, M., \& Wennerberg, J. (2003). Low Expression of Fragile Histidine Triad Gene Correlates with High Proliferation in Head and Neck Squamous Cell Carcinoma. Oral Oncol, Vol. 39, No. 1, (Jan 2003), pp. 56-63, ISSN 1368-8375

Mithani, S. K., Mydlarz, W. K., Grumbine, F. L., Smith, I. M., \& Califano, J. A. (2007). Molecular Genetics of Premalignant Oral Lesions. Oral Dis, Vol. 13, No. 2, (Mar 2007), pp. 126-133, ISSN 1354-523X

Mitra, S., Banerjee, S., Misra, C., Singh, R. K., Roy, A., Sengupta, A., Panda, C. K., \& Roychoudhury, S. (2007). Interplay between Human Papilloma Virus Infection and p53 Gene Alterations in Head and Neck Squamous Cell Carcinoma of an Indian Patient Population. J Clin Pathol, Vol. 60, No. 9, (Sep 2007), pp. 1040-1047, ISSN 0021-9746

Moriyama, M., Kumagai, S., Kawashiri, S., Kojima, K., Kakihara, K., \& Yamamoto, E. (1997). Immunohistochemical Study of Tumour Angiogenesis in Oral Squamous Cell Carcinoma. Oral Oncol, Vol. 33, No. 5, (Sep 1997), pp. 369-374, ISSN 1368-8375

Motokura, T., \& Arnold, A. (1993). Cyclin D and Oncogenesis. Curr Opin Genet Dev, Vol. 3, No. 1, (Feb 1993), pp. 5-10, ISSN 0959-437X 
Mriouah, J., Boura, C., Pinel, S., Chretien, A. S., Fifre, A., Merlin, J. L., \& Faivre, B. (2010). Cellular Response to Cetuximab in PTEN-Silenced Head and Neck Squamous Cell Carcinoma Cell Line. Int J Oncol, Vol. 37, No. 6, (Dec 2010), pp. 1555-1563, ISSN 1791-2423

Namazie, A., Alavi, S., Olopade, O. I., Pauletti, G., Aghamohammadi, N., Aghamohammadi, M., Gornbein, J. A., Calcaterra, T. C., Slamon, D. J., Wang, M. B., \& Srivatsan, E. S. (2002). Cyclin D1 Amplification and P16(Mts1/Cdk4i) Deletion Correlate with Poor Prognosis in Head and Neck Tumors. Laryngoscope, Vol. 112, No. 3, (Mar 2002), pp. 472-481, ISSN 0023-852X

Nana-Sinkam, S. P., \& Croce, C. M. (2010). MicroRNA Dysregulation in Cancer: Opportunities for the Development of MicroRNA-Based Drugs. IDrugs, Vol. 13, No. 12, (Dec 2010), pp. 843-846, ISSN 2040-3410

Narayana, A., Vaughan, A. T., Gunaratne, S., Kathuria, S., Walter, S. A., \& Reddy, S. P. (1998). Is p53 an Independent Prognostic Factor in Patients with Laryngeal Carcinoma? Cancer, Vol. 82, No. 2, (Jan 1998), pp. 286-291, ISSN 0008-543X

Nathan, C. O., Amirghahri, N., Rice, C., Abreo, F. W., Shi, R., \&Stucker, F. J. (2002). Molecular Analysis of Surgical Margins in Head and Neck Squamous Cell Carcinoma Patients. Laryngoscope, Vol. 112, No. 12, (Dec 2002), pp. 2129-2140, ISSN 0023-852X

Nees, M., Homann, N., Discher, H., Andl, T., Enders, C., Herold-Mende, C., Schuhmann, A., \& Bosch, F. X. (1993). Expression of Mutated p53 Occurs in Tumor-Distant Epithelia of Head and Neck Cancer Patients: A Possible Molecular Basis for the Development of Multiple Tumors. Cancer Res, Vol. 53, No. 18, (Sep 1993), pp. 4189-4196, ISSN 0008-5472

Negri, E., Boffetta, P., Berthiller, J., Castellsague, X., Curado, M. P., Dal Maso, L., Daudt, A. W., Fabianova, E., Fernandez, L., Wunsch-Filho, V., Franceschi, S., Hayes, R. B., Herrero, R., Koifman, S., Lazarus, P., Lence, J. J., Levi, F., Mates, D., Matos, E., Menezes, A., Muscat, J., Eluf-Neto, J., Olshan, A. F., Rudnai, P., Shangina, O., Sturgis, E. M., Szeszenia-Dabrowska, N., Talamini, R., Wei, Q., Winn, D. M., Zaridze, D., Lissowska, J., Zhang, Z. F., Ferro, G., Brennan, P., La Vecchia, C., \& Hashibe, M. (2009). Family History of Cancer: Pooled Analysis in the International Head and Neck Cancer Epidemiology Consortium. Int J Cancer, Vol. 124, No. 2, (Jan 2009), pp. 394-401, ISSN 1097-0215

Neuchrist, C., Erovic, B. M., Handisurya, A., Fischer, M. B., Steiner, G. E., Hollemann, D., Gedlicka, C., Saaristo, A., \& Burian, M. (2003). Vascular Endothelial Growth Factor $\mathrm{C}$ and Vascular Endothelial Growth Factor Receptor 3 Expression in Squamous Cell Carcinomas of the Head and Neck. Head Neck, Vol. 25, No. 6, (Jun 2003), pp. 464474, ISSN 1043-3074

Neuchrist, C., Erovic, B. M., Handisurya, A., Steiner, G. E., Rockwell, P., Gedlicka, C., \& Burian, M. (2001). Vascular Endothelial Growth Factor Receptor 2 (Vegfr2) Expression in Squamous Cell Carcinomas of the Head and Neck. Laryngoscope, Vol. 111, No. 10, (Oct 2001), pp. 1834-1841, ISSN 0023-852X

Nimeus, E., Baldetorp, B., Bendahl, P. O., Rennstam, K., Wennerberg, J., Akervall, J., \& Ferno, M. (2004). Amplification of the Cyclin D1 Gene Is Associated with Tumour Subsite, DNA Non-Diploidy and High S-Phase Fraction in Squamous Cell 
Carcinoma of the Head and Neck. Oral Oncol, Vol. 40, No. 6, (Jul 2004), pp. 624-629, ISSN 1368-8375

Nogueira, C. P., Dolan, R. W., Gooey, J., Byahatti, S., Vaughan, C. W., Fuleihan, N. S., Grillone, G., Baker, E., \& Domanowski, G. (1998). Inactivation of p53 and Amplification of Cyclin D1 Correlate with Clinical Outcome in Head and Neck Cancer. Laryngoscope, Vol. 108, No. 3, (Mar 1998), pp. 345-350, ISSN 0023-852X

Nohata, N., Hanazawa, T., Kikkawa, N., Mutallip, M., Fujimura, L., Yoshino, H., Kawakami, K., Chiyomaru, T., Enokida, H., Nakagawa, M., Okamoto, Y., \& Seki, N. (2011). Caveolin-1 Mediates Tumor Cell Migration and Invasion and Its Regulation by Mir-133a in Head and Neck Squamous Cell Carcinoma. Int J Oncol, Vol. 38, No. 1, (Jan 2011), pp. 209-217, ISSN 1791-2423

Nylander, K., Dabelsteen, E., \& Hall, P. A. (2000). The p53 Molecule and Its Prognostic Role in Squamous Cell Carcinomas of the Head and Neck. J Oral Pathol Med, Vol. 29, No. 9, (Oct 2000), pp. 413-425, ISSN 0904-2512

Okami, K., Reed, A. L., Cairns, P., Koch, W. M., Westra, W. H., Wehage, S., Jen, J., \& Sidransky, D. (1999). Cyclin D1 AmplificationIs Independent of P16 Inactivation in Head and Neck Squamous Cell Carcinoma. Oncogene, Vol. 18, No. 23, (Jun 1999), pp. 3541-3545, ISSN 0950-9232

Olivieri, E. H., da Silva, S. D., Mendonca, F. F., Urata, Y. N., Vidal, D. O., Faria Mde, A., Nishimoto, I. N., Rainho, C. A., Kowalski, L. P., \& Rogatto, S. R. (2009). Cyp1a2*1c, Cyp2e1*5b, and Gstm1 Polymorphisms Are Predictors of Risk and Poor Outcome in Head and Neck Squamous Cell Carcinoma Patients. Oral Oncol, Vol. 45, No. 9, (Sep 2009), pp. e73-79, ISSN 1368-8375

Onesto, C., Hannoun-Levi, J. M., Chamorey, E., Formento, J. L., Ramaioli, A., \& Pages, G. (2006). Vascular Endothelial Growth Factor-a and Poly(a) Binding ProteinInteracting Protein 2 Expression in Human Head and Neck Carcinomas: Correlation and Prognostic Significance. Br J Cancer, Vol. 94, No. 10, (May 2006), pp. 1516-1523, ISSN 0007-

Otero-Garcia, J. E., Youssef, E., Enamorado, II, Du, W., Yoo, G. H., Merati, K., Kewson, D., Lonardo, F., Jacobs, J. R., \& Kim, H. (2004). Prognostic Significance of p53 and Fhit in Advanced Oropharyngeal Carcinoma. Am J Otolaryngol, Vol. 25, No. 4, (Jul-Aug 2004), pp. 231-239, ISSN 0196-0709

P, O. charoenrat, Modjtahedi, H., Rhys-Evans, P., Court, W. J., Box, G. M., \&Eccles, S. A. (2000). Epidermal Growth Factor-Like Ligands Differentially up-Regulate Matrix Metalloproteinase 9 in Head and Neck Squamous Carcinoma Cells. Cancer Res, Vol. 60, No. 4, (Feb 2000), pp. 1121-1128, ISSN 0008-5472

Pai, S. I., \& Westra, W. H. (2009). Molecular Pathology of Head and Neck Cancer: Implications for Diagnosis, Prognosis, and Treatment. Annu Rev Pathol, Vol. 4, No., (Aug 2009), pp. 49-70, ISSN 1553-4014

Park, N. J., Zhou, H., Elashoff, D., Henson, B. S., Kastratovic, D. A., Abemayor, E., \& Wong, D. T. (2009). Salivary MicroRNA: Discovery, Characterization, and Clinical Utility for Oral Cancer Detection. Clin Cancer Res, Vol. 15, No. 17, (Sep 2009), pp. 54735477, ISSN 1078-0432

Partridge, M., Emilion, G., \& Langdon, J. D. (1996). Loh at 3p Correlates with a Poor Survival in Oral Squamous Cell Carcinoma. Br J Cancer, Vol. 73, No. 3, (Feb 1996), pp. 366-371, ISSN 0007-0920 
Patel, B. P., Shah, P. M., Rawal, U. M., Desai, A. A., Shah, S. V., Rawal, R. M., \& Patel, P. S. (2005). Activation of Mmp-2 and Mmp-9 in Patients with Oral Squamous Cell Carcinoma. J Surg Oncol, Vol. 90, No. 2, (May 2005), pp. 81-88, ISSN 0022-4790

Pattje, W. J., Schuuring, E., Mastik, M. F., Slagter-Menkema, L., Schrijvers, M. L., Alessi, S., van der Laan, B. F., Roodenburg, J. L., Langendijk, J. A., \& van der Wal, J. E. (2010). The Phosphatase and Tensin Homologue Deleted on Chromosome 10 Mediates Radiosensitivity in Head and Neck Cancer. Br J Cancer, Vol. 102, No. 12, (Jun 2010), pp. 1778-1785, ISSN 1532-1827

Pedrero, J. M., Carracedo, D. G., Pinto, C. M., Zapatero, A. H., Rodrigo, J. P., Nieto, C. S., \& Gonzalez, M. V. (2005). Frequent Genetic and Biochemical Alterations of the Pi 3K/Akt/Pten Pathway in Head and Neck Squamous Cell Carcinoma. Int J Cancer, Vol. 114, No. 2, (Mar 2005), pp. 242-248, ISSN 0020-7136

Perez-Ordonez, B., Beauchemin, M., \& Jordan, R. C. (2006). Molecular Biology of Squamous Cell Carcinoma of the Head and Neck. J Clin Pathol, Vol. 59, No. 5, (May 2006), pp. 445-453, ISSN 0021-9746

Perrone, F., Bossi, P., Cortelazzi, B., Locati, L., Quattrone, P., Pierotti, M. A., Pilotti, S., \& Licitra, L. (2010). TP53 Mutations and Pathologic Complete Response to Neoadjuvant Cisplatin and Fluorouracil Chemotherapy in Resected Oral Cavity Squamous Cell Carcinoma. J Clin Oncol, Vol. 28, No. 5, (Feb 2010), pp. 761-766, ISSN 1527-7755

Petrocca, F., Vecchione, A., \& Croce, C. M. (2008). Emerging Role of Mir-106b-25/Mir-17-92 Clusters in the Control of Transforming Growth Factor Beta Signaling. Cancer Res, Vol. 68, No. 20, (Oct 2008), pp. 8191-8194, ISSN 1538-7445

Petruzzelli, G. J., Benefield, J., Taitz, A. D., Fowler, S., Kalkanis, J., Scobercea, S., West, D., \& Young, M. R. (1997). Heparin-Binding Growth Factor(S) Derived from Head and Neck Squamous Cell Carcinomas Induce Endothelial Cell Proliferations. Head Neck, Vol. 19, No. 7, (Oct 1997), pp. 576-582, ISSN 1043-3074

Poeta, M. L., Manola, J., Goldwasser, M. A., Forastiere, A., Benoit, N., Califano, J. A., Ridge, J. A., Goodwin, J., Kenady, D., Saunders, J., Westra, W., Sidransky, D., \& Koch, W. M. (2007). TP53 Mutations and Survival in Squamous-Cell Carcinoma of the Head and Neck. N Engl J Med, Vol. 357, No. 25, (Dec 2007), pp. 2552-2561, ISSN 1533-4406

Pyeon, D., Newton, M. A., Lambert, P. F., den Boon, J. A., Sengupta, S., Marsit, C. J., Woodworth, C. D., Connor, J. P., Haugen, T. H., Smith, E. M., Kelsey, K. T., Turek, L. P., \& Ahlquist, P. (2007). Fundamental Differences in Cell Cycle Deregulation in Human Papillomavirus-Positive and Human Papillomavirus-Negative Head/Neck and Cervical Cancers. Cancer Res, Vol. 67, No. 10, (May 2007), pp. 4605-4619, ISSN 0008-5472

Queiroz, A. B., Focchi, G., Dobo, C., Gomes, T. S., Ribeiro, D. A., \& Oshima, C. T. (2010). Expression of P27, P21(Waf/Cip1), and P16(Ink4a) in Normal Oral Epithelium, Oral Squamous Papilloma, and Oral Squamous Cell Carcinoma. Anticancer Res, Vol. 30, No. 7, (Jul 2010), pp. 2799-2803, ISSN 1791-7530

Quon, H., Liu, F. F., \& Cummings, B. J. (2001). Potential Molecular Prognostic Markers in Head and Neck Squamous Cell Carcinomas. Head Neck, Vol. 23, No. 2, (Feb 2001), pp. 147-159, ISSN 1043-3074 
Ragin, C. C., Modugno, F., \& Gollin, S. M. (2007). The Epidemiology and Risk Factors of Head and Neck Cancer: A Focus on Human Papillomavirus. J Dent Res, Vol. 86, No. 2, (Feb 2007), pp. 104-114, ISSN 0022-0345

Ramdas, L., Giri, U., Ashorn, C. L., Coombes, K. R., El-Naggar, A., Ang, K. K., \& Story, M. D. (2009). MiRNA ExpressionProfiles in Head and Neck Squamous Cell Carcinoma and Adjacent Normal Tissue. Head Neck, Vol. 31, No. 5, (May 2009), pp. 642-654, ISSN 1097-0347

Ranelletti, F. O., Almadori, G., Rocca, B., Ferrandina, G., Ciabattoni, G., Habib, A., Galli, J., Maggiano, N., Gessi, M., \& Lauriola, L. (2001). Prognostic Significance of Cyclooxygenase-2 in Laryngeal Squamous Cell Carcinoma. Int J Cancer, Vol. 95, No. 6, (Nov 2001), pp. 343-349, ISSN 0020-7136

Reed, A. L., Califano, J., Cairns, P., Westra, W. H., Jones, R. M., Koch, W., Ahrendt, S., Eby, Y., Sewell, D., Nawroz, H., Bartek, J., \& Sidransky, D. (1996). High Frequency of P16 (Cdkn2/Mts-1/Ink4a) Inactivation in Head and Neck Squamous Cell Carcinoma. Cancer Res, Vol. 56, No. 16, (Aug 1996), pp. 3630-3633, ISSN 0008-5472

Richards, K. L., Zhang, B., Baggerly, K. A., Colella, S., Lang, J. C., Schuller, D. E., \& Krahe, R. (2009). Genome-Wide Hypomethylation in Head and Neck Cancer Is More Pronounced in Hpv-Negative Tumors and Is Associated with Genomic Instability. PLoS One, Vol. 4, No. 3, (Mar 2009), pp. e4941, ISSN 1932-6203

Ronchetti, D., Neglia, C. B., Cesana, B. M., Carboni, N., Neri, A., Pruneri, G., \& Pignataro, L. (2004). Association between p53 Gene Mutations and Tobacco and Alcohol Exposure in Laryngeal Squamous Cell Carcinoma. Arch Otolaryngol Head Neck Surg, Vol. 130, No. 3, (Mar 2004), pp. 303-306, ISSN 0886-4470

Rosenquist, K., Wennerberg, J., Annertz, K., Schildt, E. B., Hansson, B. G., Bladstrom, A., \& Andersson, G. (2007). Recurrence in Patients with Oral and Oropharyngeal Squamous Cell Carcinoma: Human Papillomavirus and Other Risk Factors. Acta Otolaryngol, Vol. 127, No. 9, (Sep 2007), pp. 980-987, ISSN 0001-6489

Rosin, M. P., Cheng, X., Poh, C., Lam, W. L., Huang, Y., Lovas, J., Berean, K., Epstein, J. B., Priddy, R., Le, N. D., \& Zhang, L. (2000). Use of Allelic Loss to Predict Malignant Risk for Low-Grade Oral Epithelial Dysplasia. Clin Cancer Res, Vol. 6, No. 2, (Feb 2000), pp. 357-362, ISSN 1078-

Rubin Grandis, J., Tweardy, D. J., \& Melhem, M. F. (1998). Asynchronous Modulation of Transforming Growth Factor Alpha and Epidermal Growth Factor Receptor Protein Expression in Progression of Premalignant Lesions to Head and Neck Squamous Cell Carcinoma. Clin Cancer Res, Vol. 4, No. 1, (Jan 1998), pp. 13-20, ISSN 1078-0432

Sanchez-Cespedes, M., Parrella, P., Nomoto, S., Cohen, D., Xiao, Y., Esteller, M., Jeronimo, C., Jordan, R. C., Nicol, T., Koch, W. M., Schoenberg, M., Mazzarelli, P., Fazio, V. M., \& Sidransky, D. (2001). Identification of a Mononucleotide Repeat as a Major Target for Mitochondrial DNA Alterations in Human Tumors. Cancer Res, Vol. 61, No. 19, (Oct 2001), pp. 7015-7019, ISSN 0008-5472

Saunders, M. E., MacKenzie, R., Shipman, R., Fransen, E., Gilbert, R., \& Jordan, R. C. (1999). Patterns of p53 Gene Mutations in Head and Neck Cancer: Full-Length Gene Sequencing and Results of Primary Radiotherapy. Clin Cancer Res, Vol. 5, No. 9, (Sep 1999), pp. 2455-2463, ISSN 1078-0432 
Schlecht, N. F., Franco, E. L., Pintos, J., \& Kowalski, L. P. (1999). Effect of Smoking Cessation and Tobacco Type on the Risk of Cancers of the Upper Aero-Digestive Tract in Brazil. Epidemiology, Vol. 10, No. 4, (Jul 1999), pp. 412-418, ISSN 1044-3983

Shahnavaz, S. A., Regezi, J. A., Bradley, G., Dube, I. D., \& Jordan, R. C. (2000). p53 Gene Mutations in Sequential Oral Epithelial Dysplasias and Squamous Cell Carcinomas. J Pathol, Vol. 190, No. 4, (Mar 2000), pp. 417-422, ISSN 0022-3417

Shiiba, M., Uzawa, K., \& Tanzawa, H. (2010). MicroRNAs in Head and Neck Squamous Cell Carcinoma (HNSCC) and Oral Squamous Cell Carcinoma (OSCC). Cancers, Vol. 2 , No. 2, (Apr 2010), pp. 653-669, ISSN 2072-6694

Shin, D. M., Mao, L., Papadimitrakopoulou, V. M., Clayman, G., El-Naggar, A., Shin, H. J., Lee, J. J., Lee, J. S., Gillenwater, A., Myers, J., Lippman, S. M., Hittelman, W. N., \& Hong, W. K. (2000). Biochemo preventive Therapy for Patients with Premalignant Lesions of the Head and Neck and p53 Gene Expression. J Natl Cancer Inst, Vol. 92, No. 1, (Jan 2000), pp. 69-73, ISSN 0027-8874

Sidransky, D. (1997). Nucleic Acid-Based Methods for the Detection of Cancer. Science, Vol. 278, No. 5340, (Nov 1997), pp. 1054-1059, ISSN 0036-8075

Sinpitaksakul, S. N., Pimkhaokham, A., Sanchavanakit, N., \& Pavasant, P. (2008). Tgf-Beta1 Induced Mmp-9 Expression in HNSCC Cell Lines Via Smad/Mlck Pathway. Biochem Biophys Res Commun, Vol. 371, No. 4, (Jul 2008), pp. 713-718, ISSN 10902104

Smilek, P., Dusek, L., Vesely, K., Rottenberg, J., \& Kostrica, R. (2006). Correlation of Expression of Ki-67, Egfr, C-Erbb-2, Mmp-9, p53, Bcl-2, Cd34 and Cell Cycle Analysis with Survival in Head and Neck Squamous Cell Cancer. J ExpClin Cancer Res, Vol. 25, No. 4, (Dec 2006), pp. 549-555, ISSN 0392-9078

Smith, E. M., Ritchie, J. M., Summersgill, K. F., Klussmann, J. P., Lee, J. H., Wang, D., Haugen, T. H., \& Turek, L. P. (2004). Age, Sexual Behavior and Human Papillomavirus Infection in Oral Cavity and Oropharyngeal Cancers. Int J Cancer, Vol. 108, No. 5, (Feb 2004), pp. 766-772, ISSN 0020-7136

Smith, E. M., Rubenstein, L. M., Hoffman, H., Haugen, T. H., \& Turek, L. P. (2010). Human Papillomavirus, P16 and p53 Expression Associated with Survival of Head and Neck Cancer. Infect Agent Cancer, Vol. 5, No., (Feb 2010), pp. 4-13, ISSN 1750-9378

Snyder, M. B., Stacey, A. J., Davis, R., Cawson, R. A., \& Binnie, W. H. (1977). The Advantages of Xeroradiography for Panoramic Examination of the Jaws and Teeth. J Periodontol, Vol. 48, No. 8, (Aug 1977), pp. 467-472, ISSN 0022-3492

Steinmann, K., Sandner, A., Schagdarsurengin, U., \& Dammann, R. H. (2009). Frequent Promoter Hypermethylation of Tumor-Related Genes in Head and Neck Squamous Cell Carcinoma. Oncol Rep, Vol. 22, No. 6, (Dec 2009), pp. 1519-1526, ISSN 17912431

Stetler-Stevenson, W. G., Liotta, L. A., \& Kleiner, D. E., Jr. (1993). Extracellular Matrix 6: Role of Matrix Metalloproteinases in Tumor Invasion and Metastasis. FASEB J, Vol. 7, No. 15, (Dec 1993), pp. 1434-1441, ISSN 0892-6638

Storey, A., Thomas, M., Kalita, A., Harwood, C., Gardiol, D., Mantovani, F., Breuer, J., Leigh, I. M., Matlashewski, G., \& Banks, L. (1998). Role of a p53 Polymorphism in the Development of Human Papillomavirus-Associated Cancer. Nature, Vol. 393, No. 6682, (May 1998), pp. 229-234, ISSN 0028-0836 
Strano, S., Dell'Orso, S., Di Agostino, S., Fontemaggi, G., Sacchi, A., \& Blandino, G. (2007). Mutant p53: An Oncogenic Transcription Factor. Oncogene, Vol. 26, No. 15, (Apr 2007), pp. 2212-2219, ISSN 0950-9232

Strano, S., Dell'Orso, S., Mongiovi, A. M., Monti, O., Lapi, E., Di Agostino, S., Fontemaggi, G., \& Blandino, G. (2007). Mutant p53 Proteins: Between Loss and Gain of Function. Head Neck, Vol. 29, No. 5, (May 2007), pp. 488-496, ISSN 1043-3074

Sturgis, E. M., Sacks, P. G., Masui, H., Mendelsohn, J., \& Schantz, S. P. (1994). Effects of Antiepidermal Growth Factor Receptor Antibody 528 on the Proliferation and Differentiation of Head and Neck Cancer. Otolaryngol Head Neck Surg, Vol. 111, No. 5, (Nov 1994), pp. 633-643, ISSN 0194-5998

Sturgis, E. M., Wei, Q., \& Spitz, M. R. (2004). Descriptive Epidemiology and Risk Factors for Head and Neck Cancer. Semin Oncol, Vol. 31, No. 6, (Dec 2004), pp. 726-733, ISSN 0093-7754

Sudbo, J., Ristimaki, A., Sondresen, J. E., Kildal, W., Boysen, M., Koppang, H. S., Reith, A., Risberg, B., Nesland, J. M., \&Bryne, M. (2003). Cyclooxygenase-2 (Cox-2) Expression in High-Risk Premalignant Oral Lesions. Oral Oncol, Vol. 39, No. 5, (Jul 2003), pp. 497-505, ISSN 1368-8375

Tai, S. K., Lee, J. I., Ang, K. K., El-Naggar, A. K., Hassan, K. A., Liu, D., Lee, J. J., Ren, H., Hong, W. K., \& Mao, L. (2004). Loss of Fhit Expression in Head and Neck Squamous Cell Carcinoma and Its Potential Clinical Implication. Clin Cancer Res, Vol. 10, No. 16, (Aug 2004), pp. 5554-5557, ISSN 1078-0432

Talamini, R., Bosetti, C., La Vecchia, C., Dal Maso, L., Levi, F., Bidoli, E., Negri, E., Pasche, C., Vaccarella, S., Barzan, L., \& Franceschi, S. (2002). Combined Effect of Tobacco and Alcohol on Laryngeal Cancer Risk: A Case-Control Study. Cancer Causes Control, Vol. 13, No. 10, (Dec 2002), pp. 957-964, ISSN 0957-5243

Tanigaki, Y., Nagashima, Y., Kitamura, Y., Matsuda, H., Mikami, Y., \& Tsukuda, M. (2004). The Expression of Vascular Endothelial Growth Factor-a and $-\mathrm{C}$, and Receptors 1 and 3: Correlation with Lymph Node Metastasis and Prognosis in Tongue Squamous Cell Carcinoma. Int J Mol Med, Vol. 14, No. 3, (Sep 2004), pp. 389-395, ISSN 1107-3756

Teknos, T. N., Cox, C., Yoo, S., Chepeha, D. B., Wolf, G. T., Bradford, C. R., Carey, T. E., \& Fisher, S. G. (2002). Elevated Serum Vascular Endothelial Growth Factor and Decreased Survival in Advanced Laryngeal Carcinoma. Head Neck, Vol. 24, No. 11, (Nov 2002), pp. 1004-1011, ISSN 1043-3074

Temam, S., Flahault, A., Perie, S., Monceaux, G., Coulet, F., Callard, P., Bernaudin, J. F., St Guily, J. L., \& Fouret, P. (2000). p53 Gene Status as a Predictor of Tumor Response to Induction Chemotherapy of Patients with Locoregionally Advanced Squamous Cell Carcinomas of the Head and Neck. J Clin Oncol, Vol. 18, No. 2, (Jan 2000), pp. 385-394, ISSN 0732-183X

Thier, R., Bruning, T., Roos, P. H., \& Bolt, H. M. (2002). Cytochrome P450 1b1, a New Keystone in Gene-Environment Interactions Related to Human Head and Neck Cancer? Arch Toxicol, Vol. 76, No. 5-6, (Jun 2002), pp. 249-256, ISSN 0340-5761

Thomas, G. R., Nadiminti, H., \& Regalado, J. (2005). Molecular Predictors of Clinical Outcome in Patients with Head and Neck Squamous Cell Carcinoma. Int J Exp Pathol, Vol. 86, No. 6, (Dec 2005), pp. 347-363, ISSN 0959-9673 
Tran, N., McLean, T., Zhang, X., Zhao, C. J., Thomson, J. M., O'Brien, C., \& Rose, B. (2007). MicroRNA Expression Profiles in Head and Neck Cancer Cell Lines. Biochem Biophys Res Commun, Vol. 358, No. 1, (Jun 2007), pp. 12-17, ISSN 0006-291X

Tsujii, M., \& DuBois, R. N. (1995). Alterations in Cellular Adhesion and Apoptosis in Epithelial Cells Overexpressing Prostaglandin Endoperoxide Synthase 2. Cell, Vol. 83, No. 3, (Nov 1995), pp. 493-501, ISSN 0092-8674

Uribe, P., \& Gonzalez, S. (2011). Epidermal Growth Factor Receptor (Egfr) and Squamous Cell Carcinoma of the Skin: Molecular Bases for Egfr-Targeted Therapy. Pathol Res Pract, Vol. 207, No. 6, (Jun 15 2011), pp. 337-342, ISSN 1618-0631

Vachani, A., Nebozhyn, M., Singhal, S., Alila, L., Wakeam, E., Muschel, R., Powell, C. A., Gaffney, P., Singh, B., Brose, M. S., Litzky, L. A., Kucharczuk, J., Kaiser, L. R., Marron, J. S., Showe, M. K., Albelda, S. M., \& Showe, L. C. (2007). A 10-Gene Classifier for Distinguishing Head and Neck Squamous Cell Carcinoma and Lung Squamous Cell Carcinoma. Clin Cancer Res, Vol. 13, No. 10, (May 2007), pp. 29052915, ISSN 1078-0432

Van Den Broek, G. B., Wildeman, M., Rasch, C. R., Armstrong, N., Schuuring, E., Begg, A. C., Looijenga, L. H., Scheper, R., van der Wal, J. E., Menkema, L., van Diest, P. J., Balm, A. J., van Velthuysen, M. L., \& Van den Brekel, M. W. (2009). Molecular Markers Predict Outcome in Squamous Cell Carcinoma of the Head and Neck after Concomitant Cisplatin-Based Chemoradiation. Int J Cancer, Vol. 124, No. 11, (Jun 2009), pp. 2643-2650, ISSN 1097-0215

Varley, K. E., Mutch, D. G., Edmonston, T. B., Goodfellow, P. J., \& Mitra, R. D. (2009). IntraTumor Heterogeneity of Mlh1 Promoter Methylation Revealed by Deep Single Molecule Bisulfite Sequencing. Nucleic Acids Res, Vol. 37, No. 14, (Aug 2009), pp. 4603-4612, ISSN 1362-4962

Vielba, R., Bilbao, J., Ispizua, A., Zabalza, I., Alfaro, J., Rezola, R., Moreno, E., Elorriaga, J., Alonso, I., Baroja, A., \& De La Hoz, C. (2003). p53 and Cyclin D1 as Prognostic Factors in Squamous Cell Carcinoma of the Larynx. Laryngoscope, Vol. 113, No. 1, (Jan 2003), pp. 167-172, ISSN 0023-852X

Volavsek, M., Bracko, M., \& Gale, N. (2003). Distribution and Prognostic Significance of Cell Cycle Proteins in Squamous Carcinoma of the Larynx, Hypopharynx and Adjacent Epithelial Hyperplastic Lesions. J Laryngol Otol, Vol. 117, No. 4, (Apr 2003), pp. 286293, ISSN 0022-2151

Wang, X., Fan, M., Chen, X., Wang, S., Alsharif, M. J., Wang, L., Liu, L., \& Deng, H. (2006). Intratumor Genomic Heterogeneity Correlates with Histological Grade of Advanced Oral Squamous Cell Carcinoma. Oral Oncol, Vol. 42, No. 7, (Aug 2006), pp. 740-744, ISSN 1368-8375

Werbrouck, J., De Ruyck, K., Duprez, F., Van Eijkeren, M., Rietzschel, E., Bekaert, S., Vral, A., De Neve, W., \& Thierens, H. (2008). Single-Nucleotide Polymorphisms in DNA Double-Strand Break Repair Genes: Association with Head and Neck Cancer and Interaction with Tobacco Use and Alcohol Consumption. Mutat Res, Vol. 656, No. 12, (Oct 2008), pp. 74-81, ISSN 0027-5107

White, R. A., Malkoski, S. P., \& Wang, X. J. (2010). Tgf beta Signaling in Head and Neck Squamous Cell Carcinoma. Oncogene, Vol. 29, No. 40, (Oct 2010), pp. 5437-5446, ISSN 1476-5594 
Wilken, R., Veena, M. S., Wang, M. B., \& Srivatsan, E. S. (2011). Curcumin: A Review of Anti-Cancer Properties and Therapeutic Activity in Head and Neck Squamous Cell Carcinoma. Mol Cancer, Vol. 10, No., (Feb 2011), pp. 12-31, ISSN 1476-4598

Wong, R. H., Du, C. L., Wang, J. D., Chan, C. C., Luo, J. C., \& Cheng, T. J. (2002). Xrcc1 and Cyp2e1 Polymorphisms as Susceptibility Factors of Plasma Mutant p53 Protein and Anti-P53 Antibody Expression in Vinyl Chloride Monomer-Exposed Polyvinyl Chloride Workers. Cancer Epidemiol Biomarkers Prev, Vol. 11, No. 5, (May 2002), pp. 475-482, ISSN 1055-9965

Wong, T. S., Ho, W. K., Chan, J. Y., Ng, R. W., \& Wei, W. I. (2009). Mature Mir-184 and Squamous Cell Carcinoma of the Tongue. Scientific World Journal, Vol. 9, No., (Feb 2009), pp. 130-132, ISSN 1537-744X

Wong, T. S., Liu, X. B., Chung-Wai Ho, A., Po-Wing Yuen, A., Wai-Man Ng, R., \& Ignace Wei, W. (2008). Identification of Pyruvate Kinase Type M2 as Potential Oncoprotein in Squamous Cell Carcinoma of Tongue through MicroRNA Profiling. Int J Cancer, Vol. 123, No. 2, (Jul 2008), pp. 251-257, ISSN 1097-0215

Wong, T. S., Liu, X. B., Wong, B. Y., Ng, R. W., Yuen, A. P., \& Wei, W. I. (2008). Mature Mir184 asPotential Oncogenic MicroRNA of Squamous Cell Carcinoma of Tongue. Clin Cancer Res, Vol. 14, No. 9, (May 2008), pp. 2588-2592, ISSN 1078-0432

Wreesmann, V. B., \& Singh, B. (2005). Chromosomal Aberrations in Squamous Cell Carcinomas of the Upper Aerodigestive Tract: Biologic Insights and Clinical Opportunities. J Oral Pathol Med, Vol. 34, No. 8, (Sep 2005), pp. 449-459, ISSN 09042512

Yin, X. Y., Smith, M. L., Whiteside, T. L., Johnson, J. T., Herberman, R. B., \& Locker, J. (1993). Abnormalities in the p53 Gene in Tumors and Cell Lines of Human Squamous-Cell Carcinomas of the Head and Neck. Int J Cancer, Vol. 54, No. 2, (May 1993), pp. 322327, ISSN 0020-7136

Youssef, E. M., Lotan, D., Issa, J. P., Wakasa, K., Fan, Y. H., Mao, L., Hassan, K., Feng, L., Lee, J. J., Lippman, S. M., Hong, W. K., \& Lotan, R. (2004). Hypermethylation of the Retinoic Acid Receptor-Beta(2) Gene in Head and Neck Carcinogenesis. Clin Cancer Res, Vol. 10, No. 5, (Mar 2004), pp. 1733-1742, ISSN 1078-0432

Yuen, P. W., Man, M., Lam, K. Y., \& Kwong, Y. L. (2002). Clinicopathological Significance of P16 Gene Expression in the Surgical Treatment of Head and Neck Squamous Cell Carcinomas. J Clin Pathol, Vol. 55, No. 1, (Jan 2002), pp. 58-60, ISSN 0021-9746

Zhang, Z. F., Morgenstern, H., Spitz, M. R., Tashkin, D. P., Yu, G. P., Hsu, T. C., \& Schantz, S. P. (2000). Environmental Tobacco Smoking, Mutagen Sensitivity, and Head and Neck Squamous Cell Carcinoma. Cancer Epidemiol Biomarkers Prev, Vol. 9, No. 10, (Oct 2000), pp. 1043-1049, ISSN 1055-9965

Zidar, N., Bostjancic, E., Gale, N., Kojc, N., Poljak, M., Glavac, D., \& Cardesa, A. (2011). Down-Regulation of MicroRNAs of the Mir-200 Family and Mir-205, and an Altered Expression of Classic and Desmosomal Cadherins in Spindle Cell Carcinoma of the Head and Neck--Hallmark of Epithelial-Mesenchymal Transition. Hum Pathol, Vol. 42, No. 4, (Apr 2011), pp. 482-488, ISSN 1532-8392 


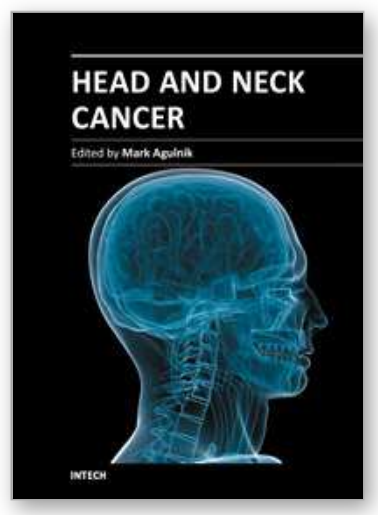

\author{
Head and Neck Cancer \\ Edited by Dr. Mark Agulnik
}

ISBN 978-953-51-0236-6

Hard cover, 440 pages

Publisher InTech

Published online 14, March, 2012

Published in print edition March, 2012

Head and Neck Cancer provides an interesting and comprehensive overview of all aspects of head and neck cancer including overviews of the disease, basic science aspects pertaining to the disease, diagnosis,

treatment and outcomes for patients with this disease. The chapters written by world renowned experts cover the entire discipline of head and neck oncology and include discussions of regional disparity is, advances in basic science understanding, advances in her radiotherapy, chemotherapy and targeted agents as well as a focus on reconstruction, prostheses, and aspects of quality of life and health outcomes. The book is designed to be both practical and comprehensive for every physician treating his complex disease.

\title{
How to reference
}

In order to correctly reference this scholarly work, feel free to copy and paste the following:

Federica Ganci, Andrea Sacconi, Valentina Manciocco, Renato Covello,Giuseppe Spriano, Giulia Fontemaggi and Giovanni Blandino (2012). Molecular Genetics and Biology of Head and Neck Squamous Cell Carcinoma: Implications for Diagnosis, Prognosis and Treatment, Head and Neck Cancer, Dr. Mark Agulnik (Ed.), ISBN: 978-953-51-0236-6, InTech, Available from: http://www.intechopen.com/books/head-and-neckcancer/molecular-genetics-and-biology-of-head-and-neck-squamous-cell-carcinoma-implications-fordiagnosis-p

\section{INTECH}

open science | open minds

\author{
InTech Europe \\ University Campus STeP Ri \\ Slavka Krautzeka 83/A \\ 51000 Rijeka, Croatia \\ Phone: +385 (51) 770447 \\ Fax: +385 (51) 686166 \\ www.intechopen.com
}

\author{
InTech China \\ Unit 405, Office Block, Hotel Equatorial Shanghai \\ No.65, Yan An Road (West), Shanghai, 200040, China \\ 中国上海市延安西路65号上海国际贵都大饭店办公楼 405 单元 \\ Phone: +86-21-62489820 \\ Fax: +86-21-62489821
}


(C) 2012 The Author(s). Licensee IntechOpen. This is an open access article distributed under the terms of the Creative Commons Attribution 3.0 License, which permits unrestricted use, distribution, and reproduction in any medium, provided the original work is properly cited. 